\title{
The Relationship Between Interior Architecture and Music
}

\author{
Essam Metwally Mohamed ${ }^{1}$ \\ ${ }^{1}$ Interior Design Department, Faculty of Architecture and Design, University of Petra, Amman, Jordan \\ Correspondence: Essam Metwally Mohamed, Interior Design Department, Faculty of Architecture and Design, \\ University of Petra, Amman-Jordan. University of Petra, Amman, Airport Main Road, P.O. Box 961343, Amman \\ 11196, Jordan. E-mail: esammet@yahoo.com
}

Received: August 16, 2018

doi:10.5539/mas.v12n10p86

\author{
Accepted: August 31, 2018 \\ Online Published: September 26, 2018 \\ URL: https://doi.org/10.5539/mas.v12n10p86
}

\begin{abstract}
There is no doubt that there is a calculated relationship between architecture and music. If music is the translation of emotion, this emotion has been reflected in the architectural character and the arts of building and shaping its style. And the music of primitive tribes and barbaric peoples represented by the drums of homogeneous repetitions reflected on their buildings and primitive character or their huts identical and compact without compatibility or homogeneity. The rural music of each country, which is characterized by simple melodies and monotonous tones belonging to the living nature and sprouts from its land, we find a reflection of the buildings that are characterized by simplicity and calm and building materials derived from the surrounding nature.

The Harmonized melodies and the continuous repetition of original tones and their background can easily be read or heard on the facades of the Islamic style buildings in the continuous surface repetition of contracts and decorations

The change of the personality of Arab architecture from one country to another and the change of the form of contracts and domes, has found a similarity in the changing personality of contemporary music.

Every modern development in architecture and its character is recorded by the music and its character. The more the cultures of the peoples are merged, the more modern the modern architecture, which occupies its place in the different countries, resonates with contemporary world music and converges with the civil affinity and culture of the peoples.

"Architecture is music embodied in the place," says Hassan Fathi. "Music is an architecture embodied in time"

Studying the relationship between interior architecture and music enables us to "enjoy" it by using our senses to "see what we listen to" and "hear what we see" achieve greater levels of experience. I think this is what the "normal" people do, and they use their senses to live life differently than they did before.

Through practical experiments for students of Design 2, the music has been transformed into an interior design through the sensation, sensation and impression of the music in the same designer to translate these feelings into design forms and stereoscopic elements with materials, colors and reflections that express these feelings and the emotional state raised by this music.
\end{abstract}

\section{Introduction}

The Classical music in every country, including complexity, simplicity, superficiality or depth, has found a clear reflection on the architecture of its contemporary and its music and its tones on the facades of buildings, their decorations and their composition. The relationship between Italian opera music, the Italian Renaissance style, the German opera, the German architecture, or the French architecture of the era confirms that the music of each of these countries is only the language of architecture itself, or that it has frozen to form.

\subsection{The Problems}

Students studying interior design lack a sense of proportion and harmony between the elements of the space, and look at it with a Sensitivity and also control the relationship between openings, windows, doors, furniture, walls, ceilings and floors. Between materials, colors and lighting

\subsection{The Objectives}

The research aims to teach the student the principles of interior design through the connection between music and 
design and how to translate the melody, rhythm and other means of output music to architectural elements. And how to express the imaginary things we hear and there is only in our minds only to a space we live in, and outlet various materials, different colors and multiple texture to produce Interior design carries the qualities of beauty through harmony, rhythm and repetition, which are the languages that we gain from music.

\section{Important Definitions}

Music: It is an art composed of voices and silence over a period of time

Sound Layer: Include Harmony, and Rhythm

Melody: Each toned voice is heard by the ear and restores it

Golden Ratio: Known since "Euclid" and used in many human works as aesthetic standards of proportion

Design: Design is the collection of some components and processing and the necessary work of the treatment, measurement and modification and add the element of innovation and beauty to them, to come out with a product or something new and distinctive, functioning effectively, and meet the purpose of design.

Design elements: Design elements are things that must be studied and considered when designing anything that we want as a painting, plan, or other. These elements start from the point, the line and then the shape and texture, in addition to the color that gives beauty or more clarity to the design. The space is part of the design elements. In addition to composition, expression, balance and characternterior design: The art of remediation the interior space and all its dimensions using all elements of interior design in an aesthetic and functional way helps to work inside the building.

Repetition: Repetition of design elements can be used to illustrate and confirm a certain rhythm. Repetition can add visual importance to the design, and helps identify sets of elements that belong to each other. Repetition can be considered as a way to add consistency to the design. The intensity of repeating elements works to create an optical unit.

Balance: refers to the principle of visual balance. Optical stability of certain geometric components can also result in conflicting elements

Symmetry: refers to the process of organizing elements of a graphic according to a hierarchical balance achieved by aligning the elements in relation to the direction of the axial line which can be vertical, horizontal, or oblique. That is, the parts of the design correspond to each other - for a central axis - as a mirror image.

In contrast, design elements that show an optical imbalance, consist of different elements in space, color and shape, positioned against each other to create contrast.

Module: The basic principle that combines elements of design in a single configuration. The unit indicates that all elements of the composition work in harmony as one element. This can be achieved through the use of continuity and geometric transformation between design elements. In addition, repetition and stereotyping are among the most important factors for creating a strong sense of unity

Rhythm: The rhythm is the basis of the foundations of the design, which appears in the case on which the element visible in the work of art. And can be a visual rhythm, surprising and others sequential or reciprocal. This repetition in blocks, spaces or shapes may consist of units that may be completely identical or different, close or spaced, and between each base a distance is called a period

\section{Research Methodology (Experimental Methodology)}

The study examines the effect of pre-set changes on the problem or objective. Various types of music and instruments are studied. Through study, listening to music and discovering the relationship of each tone to the design. The music translates into a line, a space, a form, a color, a material, a light, and the design finally express the type of music chosen the content.

\section{The Music}

Music is an art of voices and silence over a period of time. The characteristics of the sound that describe the music are the pitch, including the rhythm, the balance, the sound quality of the timbre, the articulation, the dynamics, and the texture.

The Scientists believe the history of musical life that the word Greek music origin. It used to mean the arts in general, but later became only melodic. The word "music" has been defined as melody, an industry in which it seeks to organize the melodies and the relationships between them, the rhythms and their weights. Music is the art of looking for the nature of melodies in terms of agreement and dissonance. 
Despite the fact that people are trying to preserve their culture, especially their musical ones, as a result of the influence of cultures on each other, international musical schools entered every home in the universe. New schools were also created in other arts, such as plastic arts, sculpture, architecture, theater and literature. But music, along with poetry and architecture, is one of the most important elements of cultural heritage, which defines and distinguishes the culture of societies and reflects their development. "If you want to know a country and look at its development, you have to hear its music," says Confucius.

The Music originated in Europe in the year 500 AD, where it began in the hymns of churches and then developed into the music known in the Renaissance era from the beginning of the 14th and 15th centuries, which was known in modern art. Where music scores have reached a high degree of progress and multi-tone music has reached an unprecedented degree of complexity.

From 1750 to 1800 , music, later known as classical music, was characterized by the emergence of musical symphonies

Towards the end of the 19th century, the influential school emerged as a reaction to romance. In 1860, there was a radical revolution in the field of music known as the new music. There were many anti-romantic trends in the 20th century, where the new classic

The New music also appeared, such as jazz music, which accompanied African migrations to America and Europe, and modern music such as pop music, rock and roll, country music,

The AB Music consists of seven sounds (scores or marks) forming a musical ladder or scale

Ladder Music is a collection of vocal tones that we use in singing. The musical track is used to record musical notes on the lines and spaces, which are five lines parallel and equal in length and dimensions. With four spaces starting and counting the lines of the music runway from the bottom up. The line in the musical track takes its musical mark, according to the music key on the first runway and the musical track is divided into equal time scales. This division is done by vertical lines on the musical runway and is called scale separators. At the end of the piece, a double piece is placed at the end of the melody

\subsection{About the Science of Melody}

The melody is a toned sound that the ear hears and relaxes. Whether it is human, bird, nature, or a machine.

And the musical tones are only a language of seven letters only. And you can imagine that these seven tones are the formulation of all the melodies, no matter how many or multiple. The following picture shows the rise of tones by recording them in a sound program So the music ladder is a seven-tone upward.

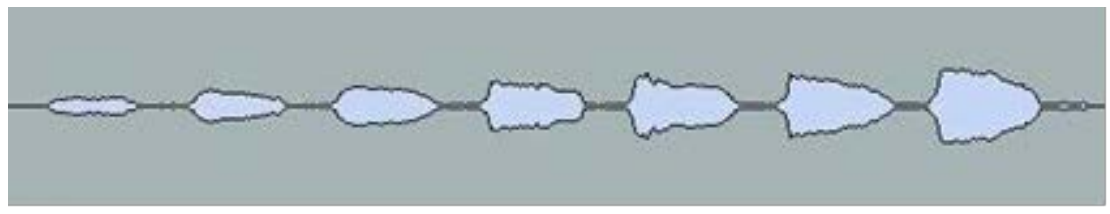

Figure 1 . The music ladder is a seven-tone upward

\subsection{The Basic Characteristics of Sound}

The basic characteristics of sound consist of only four fundamentals; pitch, duration, quality and intensity, however, the character of the sequence of sounds and its arrangement is what makes a music subjectively pleasing and individually enjoyed. Pitch (including melody and harmony), Rhythm (including scales) The sound quality of both the timbre, the articulation, the dynamics, and the texture.

\subsection{What is the Difference Between Balance and Rhythm?}

We often confuse Balance and rhythm (in music as in architecture) and interact with Balance as rhythms, and vice versa. Although Balance is only a constant cut off time. While rhythm, movement, mixing and crushing permanent (within Balance, or outside). In music we divide the times and put them in uniform, to form a constant Balance. The rhythm in the music is formed by the sounds of control and control, strokes, and strengths in the melody, a word or music abstract.

\subsection{The Importance of Rhythm of Music}

Most historians agree that the origin of music anywhere began to rhythm, hence everyone considers rhythm is the first element of the four music. The rhythm is the regular pulse measured by time, that is, all that is related to the 
temporal aspect of musical sound. It can be said that it organizes the musical sounds that make up any tune into equal time units, containing equal units of repetitive rhythmic pulse. The pulses may be divided into each sphere in equal or different proportions, and this difference and variation is what gives each rhythm its taste and color. If we have a set of several degrees of sound and we have two or more different rhythmic formulas, the musical character of that sentence will vary radically.

\subsection{Meaning, Rhythm and Force}

As abstract art forms based on rhythm, proportion and harmony, architecture and music share a clear cultural lineage. Now, through digital expression, architecture can attain new heights of creative supremacy

'All art' Walter Pater famously observed in 1877, 'constantly aspires towards the condition of music.' Why the music envy? Because, the standard answer goes, in abstract music the form and content - or in its case the sound and sense - are one integrated thing. Peters aphorism became a good prediction of the zeitgeist and the goal of abstract art in 30 years as the painters in Paris and elsewhere pursued a kind of visual equivalent of musical themes, and Expressionist and Cubist architects followed suit. Indeed, architecture as 'frozen music' had a long history of tracking its sister, the parallel art of harmonic and rhythmic order. Many qualities unite these two art forms - and quite a few make them different - but it is the former I find compelling today. Their shared concerns can be seen in ceremonial architecture from the ancient Brodgar Stone Circle to concert halls, in structures that heighten the senses and make one perceive more sharply and emotionally. In an era when museums and other building types emerge as a suitable place for musical ornament, and when expressive shapes can be produced digitally, architecture could reach its supreme condition once again and become its own particular kind of music.

\subsection{What is the Rhythm of Country Music?}

A lot of slow and a little bit of fast, but most slow in places

\subsection{How do You Find Rhythm in Music?}

You need to be able to hear the main beats and the subordinate beats. Often these beats are emphasized by drumming. Try walking "in time with the music"; your steps will probably fall on the principal beats.

\subsection{Which Style of Music Relies on the Rhythm?}

Practically every style of music relies on rhythm. I can't think of any music that doesn't. Most musical pieces have a certain set number of beats to a bar as well as a set tempo.

\section{Music in Interior Design}

\subsection{Rhythm and Repetition}

One of the most important ways to reach a unit in the building is by repeating elements such as windows and columns. And the existence of similarities and simple between the elements is one way to confirm the relationship and union.

The importance of rhythm in architecture lies in the existence of a relationship between them and between human rhythm such as movement, breathing and natural rhythms such as the sea wave and the seasons of the year. Just as music represents the audible rhythms, the architecture represents visual rhythms. In architecture, the foundation is to try to reach the rhythm in the distances between the components. The visual rhythm of the building depends on the components and distances between them. There are two basic types of rhythm that can be identified: 1) regular rhythm between components on the basis of identical units and regular distances, and 2) the rhythm consisting of spacing between components and distances. Rhythms can also be obtained from different distances and components of varying size in addition to increasing or decreasing rhythms. (Figure 2)

\subsection{Alternation}

Alternation is used to create rhythm by alternating two or more elements in a regular pattern. The pattern may be $\mathrm{ABCABC}$ or $\mathrm{ABBABB}$, but always repeating in the same order. (Figure 3)

\subsection{Progression}

Rhythm can also be achieved through progression. Examples are a gradation of colour or a series of objects that start small and become large in a very regular manner. (Figure 4) 


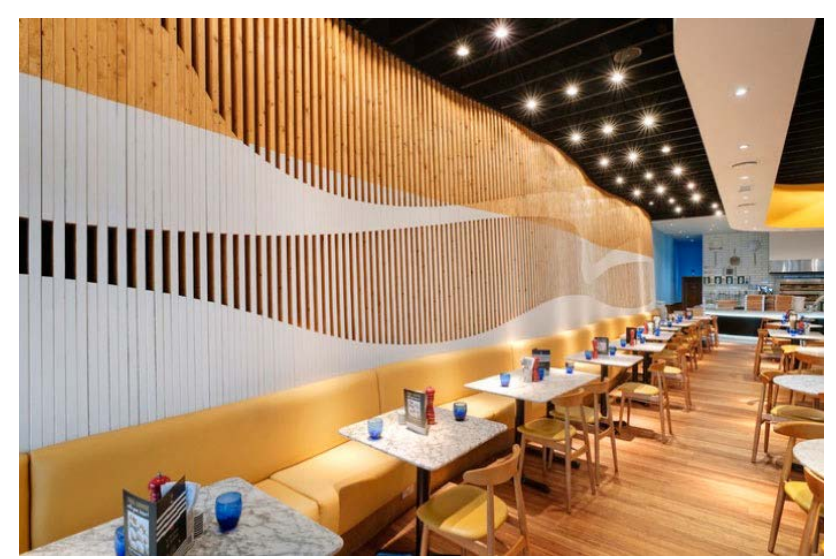

Figure 2. The Repeating Wood Slats on the Wall of this Pizza Shop by Baynes \& Co Designers Creates a Playful Rhythm and Draws Your Eye Through the Space

In interior design, rhythm is all about repetition of design elements that help to create movement within a space. The rhythm may be applied in bold statements that make an obvious suggestion about a path of travel, or more subtly applied to move your eye about a space without you even realizing the rhythm is there.

How does harmony give weight and depth to a song melody exactly? Each chord has its own 'colour' or perspective, and often seems to also have a direction of travel. It takes you to the next point in the song, either with a feeling of inevitability, or alternatively with a sense of sudden unexpected shock! (Note 1)

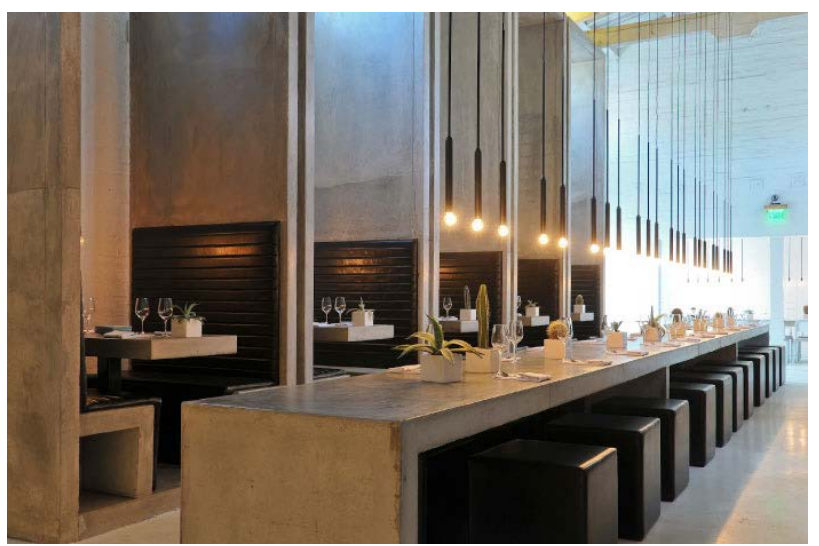

Figure 3. This restaurant by some architects displays both repetitive rhythm, in the booths and chairs, as well as alternation which can be seen in the pendant lights that hang in groupings with an abaaaaba rhythm

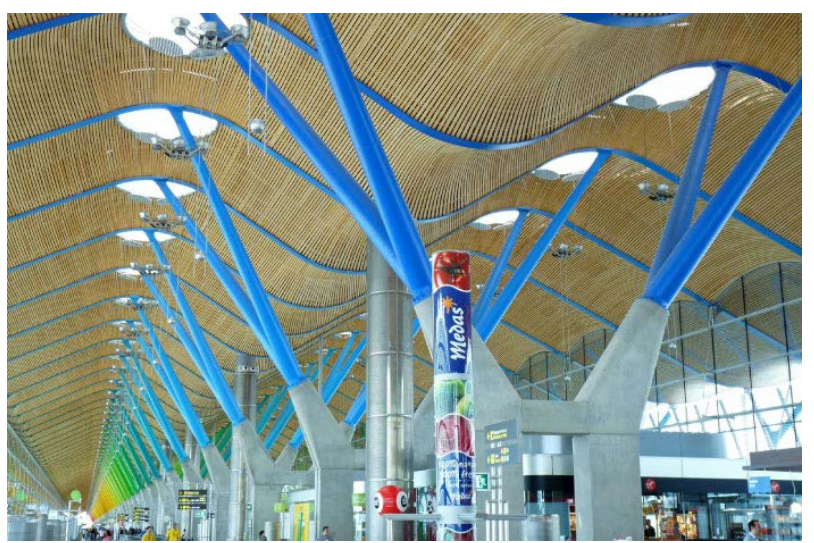

Figure 4. The Barajas airport - by Richard rogers and studio lamella is an excellent example of rhythm achieved through repetition and progression of color 


\subsection{Harmony}

\section{General definition}

- It is a consensus between votes

- A sequential set of score sounds to be a sweet voice

- Definition of harmony in architecture

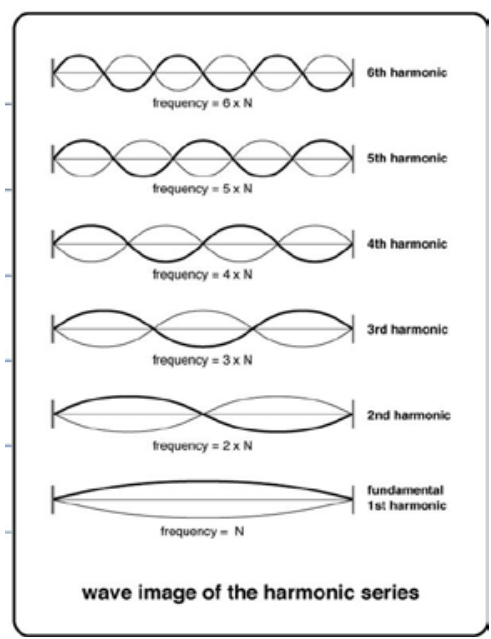

Figure 5. The Harmonic Series

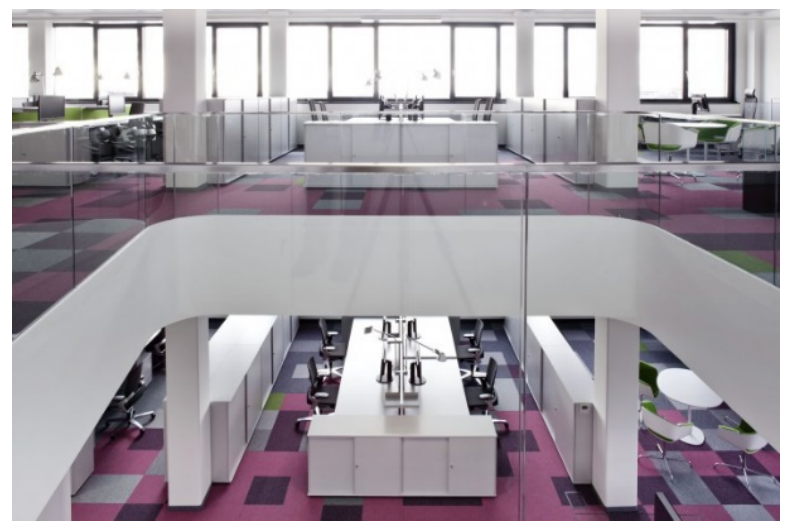

Figure 6. Beef architeckten's design for this pipe office uses color, pattern and shape as harmonious elements in at least a couple of floors of open workstations

It is related to the whole part is a link colors between them is the relationship between the various elements of the building such as windows and doors, The harmony between the linear maximum limits which means (control and lack of diversity and change) and the lack of harmony and mean dissonance, and includes the properties of the two together and the degree of approach design of one of the extremes depends on the ideas to be asked and the design function. (Figure 6)

\subsection{Unity}

Unity is the fundamental principle that combines all principles and elements of design into a single structure. The unit indicates that all elements of the composition work in harmony as one element. This can be achieved through the use of continuity and geometric transformation between graphical elements. In addition, repetition and stereotyping are among the most important factors for creating a strong sense of unity. The unity or harmony means the combination of the basic elements of the design, so that the whole unit is harmonious, so the designer must make sure before adding the furniture in the room, that the color, texture, shape and lines of the piece are naturally combined with the elements of the room. (Figure 7) 


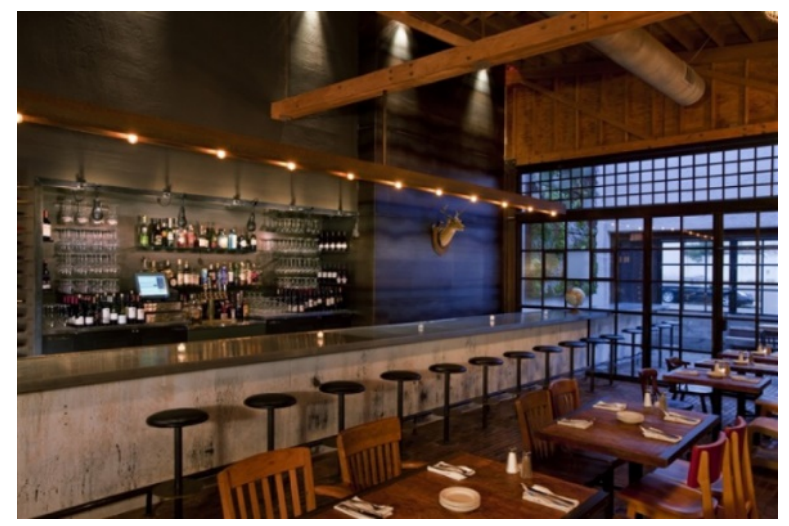

Figure 7. The banker's hill bar and restaurant in San Diego's rustic finishes, exposed structure, eclectic collection of chairs and deer mount all work together to create a cozy, unified space

\section{Music and Art}

The works that represent the peak of the artistic maturity of Kandinsky are concentrated in his time in Paris between 1933 and 1944. Kandinsky emphasized at that time that abstract works can be compared to music, as music is the top of abstraction which He addressed the soul directly. He emphasized that form, colour and handwriting are the language of the photographer who best communicates his emotion directly to the recipient's soul. The musician also does not resemble a material form in reality, so he was interested in rhythm, melody and colour harmony. It has only a numeric sequence for each "Movement", and one of these works plate (movement) and carried out in 1935. (Figure 8).

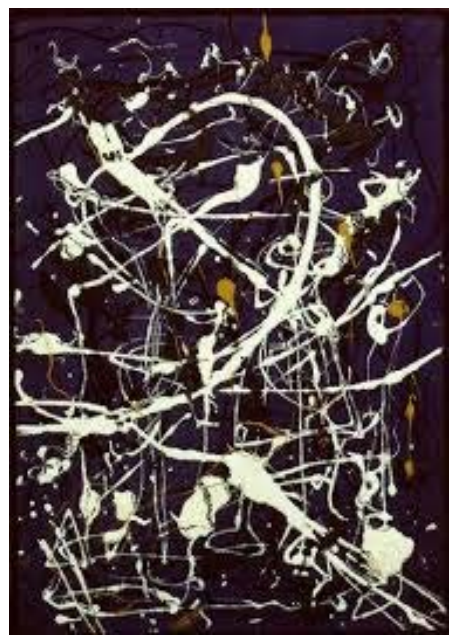

Figure 8. Kandinsky (Movement)

\section{Inspire Music from Architectural Concept (Golden Ratio)}

The Golden Ratio or the Golden Number 1.618 A simple figure in its form and at first sight is a very ordinary number, but in fact it is one of the most controversial figures in history. It is a percentage that earns every job we do in all areas of life. If we use it, it is beautiful and sophisticated. Creative work. (A measure of beauty and one of the secrets of beauty around us in this universe).

The Golden Ratio, the Golden Number, the Divine Ratio or the Number Faye are all names that began to appear after Leonardo Fibonacci's work on the famous sequence named "Fibonacci number"

The golden ratio is simple:) suitable for lengths )between two numerical values that achieve that ratio. (The proportion of full length of the large part, such as the proportion of the large part of the small) - If we assume that we have a wire of a certain length and was divided into two parts by 1: 2 
The ratio of the total length of the wire of the bulk of it: the proportion of the bulk of the smaller part. The value of the golden ratio is expressed in mathematical rigidity: 1.61803399 It is expressed by the Greek letter " $\varphi$ " The Golden Ratio, the Golden Number, the Divine Ratio or the Number Faye are all names that began to appear after Leonardo Fibonacci's famous work called "Fibonacci number" (Figure 9).

And numbers that follow the following format: $0,1,1,2,3,5,8,13,21,34,55,89,144$ is the product of the sum of the previous two numbers, Each number by 1.618 bit by bit

It is also known that the ratio is not only linked to straight lines, but also has different forms and different names. For example, this all-famous spiral is based on the golden ratio, but it works more than once in a way that overlaps with each turn. Thus, we can measure in the vast artistic fields in its beauty, drawings, sculptures, buildings and everything supposed Be nice as well as music

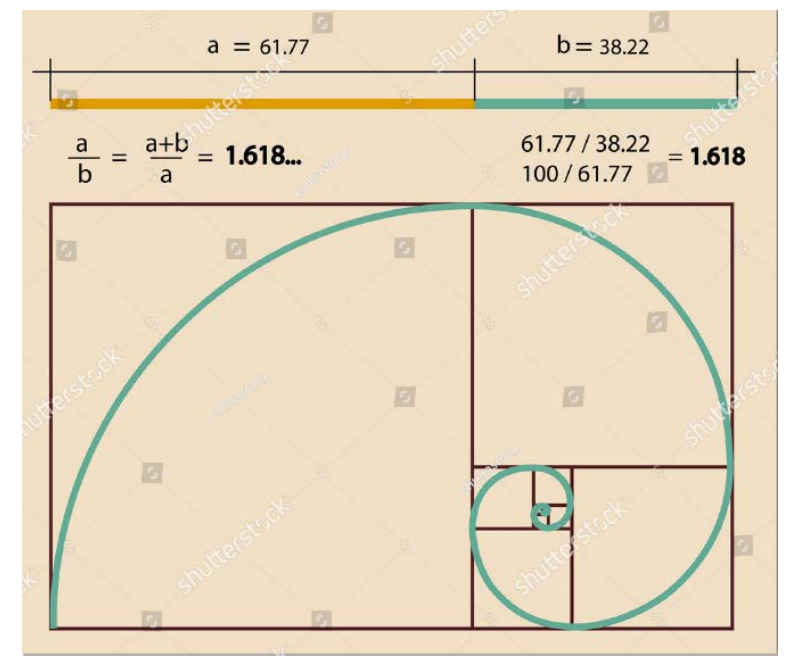

Figure 9. The golden ratio of Fibonacci

\subsection{Proportionality and Music}

The Music is not only a collection of notes that compose music harmony, but is a rhythm and harmony of sounds and a change of musical marks with time. Interestingly, when we analyze a particular piece of music, we are likely to find a mathematical appendage that links two music pieces. There is a lot of controversy about Mozart's use of the gold ratio in his music, and whether he has set the standards using mathematical equations or a thousand of his music from everyday life! (Figure 10).

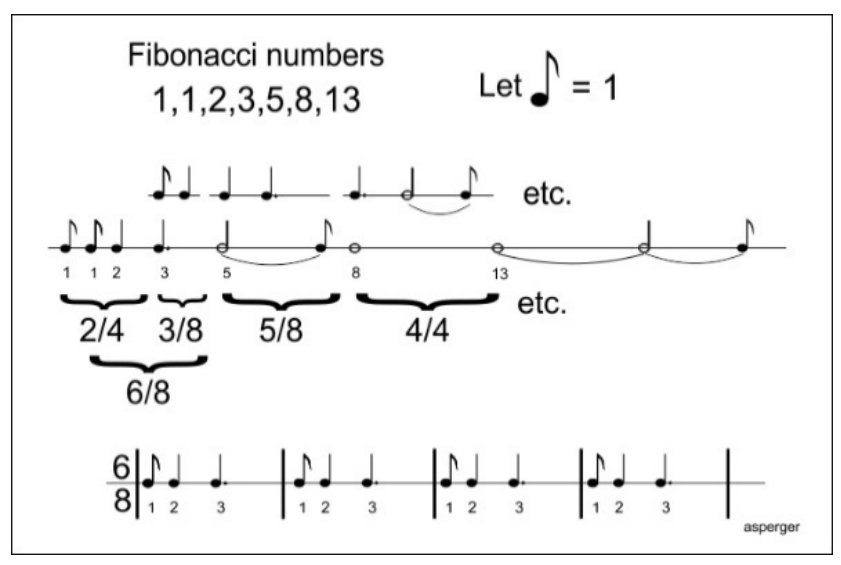

Figure 10. Proportionality in music

\subsection{Proportionality and Music}

The Music is not only a collection of notes that compose music harmony, but is a rhythm and harmony of sounds and a change of musical marks with time. Interestingly, when we analyze a particular piece of music, we are likely 
to find a mathematical appendage that links two music pieces. There is a lot of controversy about Mozart's use of the gold ratio in his music, and whether he has set the standards using mathematical equations or a thousand of his music from everyday life! (Figure 11).

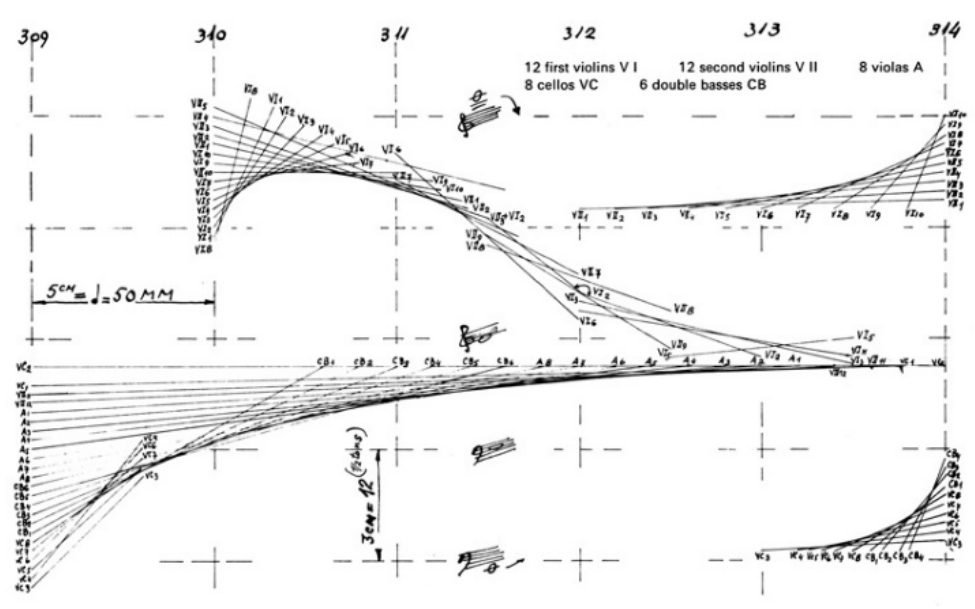

Figure 11. Xenakis work

\section{Inspiration of Architectural Thought of Music}

Xenakis escaped to France from Greece in 1947, a death sentence on his head. Upon arriving in Paris, which became his permanent home, he landed a job as an engineer for Le Corbusier. His love of curving forms and irregular patterns — and his skill in bringing them to life-had a perceptible effect on two major Le Corbusier structures: the monastery at Sainte-Marie de la Tourette, with its undulating glass façade, and the Philips Pavilion at the 1958 Brussels World's Fair, with its paraboloidal shape. Yet music ultimately exerted a stronger hold. Messiaen, whose Catholic mysticism might seem far removed from Xenakis's radical rationalism, played a pivotal role in his development. Messiaen advised his student not to choose among his diverse interests, but to unite them: "Be Greek, be a mathematician, be an architect, and out of it all make music!” (Note 2) (Figure 12\&13).
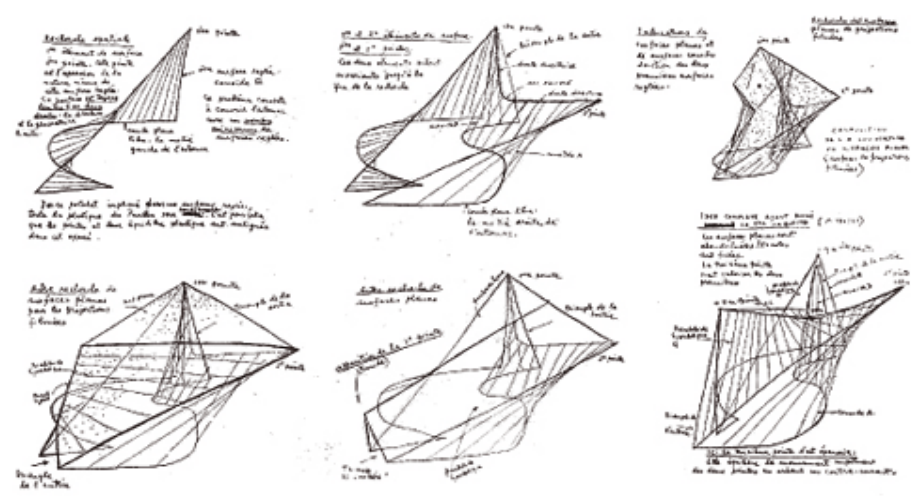

Figure 12. The Philips Pavilion at the 1958 Brussels World's 


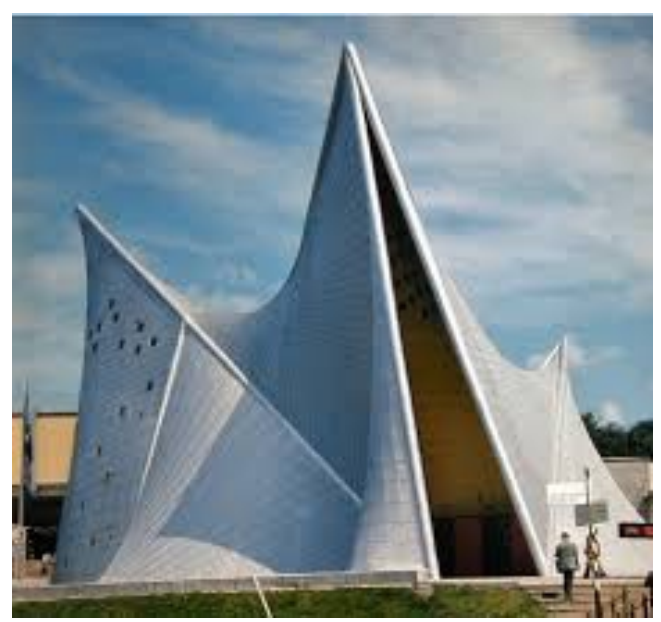

Figure 13. Expo '58 + Philips Pavilion / Le Corbusier and Iannis Xenakis

\subsection{Xenakis, Independent Architect}

Xenakis then worked as an independent engineer for a construction business, while focusing as much as possible on his musical and mathematical research. The contacts he had made with Hermann Scherchen in the mid-1950s had been decisive. Thanks in part to his visits to Gravesano, where the annual meetings of young composers took place, Xenakis found the courage to devote himself entirely to music, although Scherchen had always urged him not to completely abandon architecture. In 1961, Scherchen asked Xenakis to consider a studio that he wanted to create for experimental music in Gravesano! Abandoned at the project-conception stage, it was only in 1984, during the competition for the Cité de la Musique in Paris, that Xenakis was able to pick up this project, which had expressed strong desire to break with the tradition of frontal listening. In addition to a large range of musical equipment, his proposal, which was drawn up together with Jean-Louis Véret (another former member of the Le Corbusier team), included a great, 2500-seat concert hall shaped as a "patatoid". It was equipped with a ramp deployed in a constant helical shape around the hall. The spectator would be "suspended in space like a spider at the tip of its thread. The hall itself was, in turn, enveloped in hyperbolic sails made of reinforced concrete. Since the volume of air between the sail and the room could be regulated via pivoting panels in the walls, this mechanism could vary the volume of air in the hall and thus dose its sound energy, depending on the composition or the instruments to be played. With its "resonance chamber", the hall, thus actually functioned as a musical instrument itself! (Note 3) (Figure 14).

Le Corbusier collaborated with composer and architect Iannis Xenakis for the first time to achieve its goal of using electronic media in design based on hyperbolic geometry and parabola parabola - and how this ambitious vision is achieved through an innovative system of prefabricated concrete panels designed by Duyster

Xenakis moved deftly between disciplines and increased his command and control by using each to critique the other. For any serious student of architecture who enjoys music, this show is a fantastic reinforcement of the idea that "architecture is frozen music." The creatures walk us through the intense yet beautiful working process of a brilliant mind dedicated to showing exactly how music is both architecture and mathematics-and how they are all, ultimately, about space. (Note 4) (Figure 14).

The relationship between architecture and music is an old classical one, and Le Corbusier cooperated with Zenax in introducing a work such as magic in our modern era, the Grace-Music Hall and an architecture similar to Modern Surrealism Music.

His interest in re-establishing the relationship between music and exterior and interior architectural design from the beginning focused on common aspects such as Continuity, Rhythm, Orientation and Style, set in silent tones similar to makeup, found throughout the building in varying degrees of density. (Figure 14). 

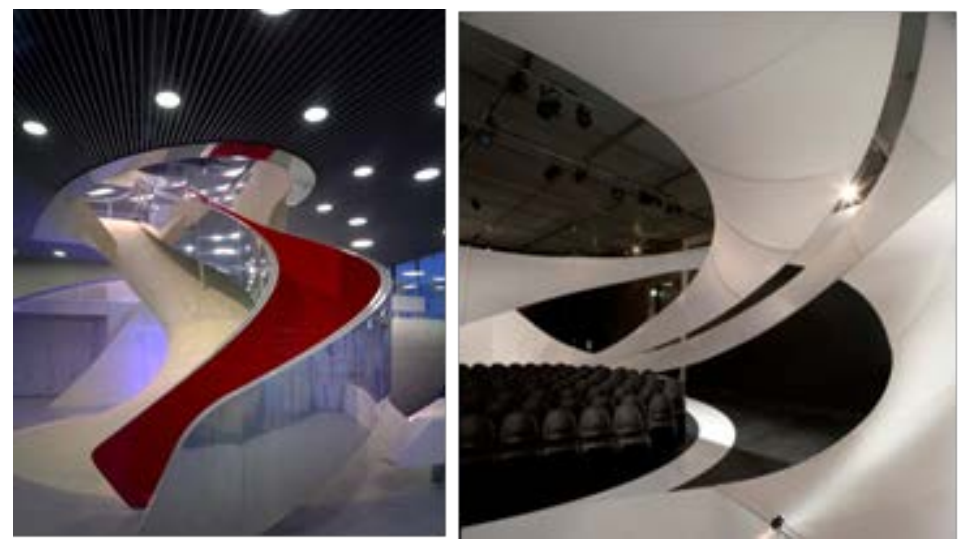

Figure 14. Concert hall

Zaha Hadid Architects considered the amazing Bach music when the Chamber Music Hall was designed. The architectural design of the music hall is like frozen music. It is a wavy steel structure covered by a transparent membrane. This fabric is specially designed for a solo performance of chamber music.

The creation of iron designed in the form of ribbons hovering over the stage and damaged the concert hall.

It expresses the visual representation of the great music of the Baroque musician Johann Sebastian Bach, which gives us a distinctive picture of how music is used in geometrical geometry in an integrated interior design that enhances Bach's multiple works through the integration of formal and structural logic.

The design of the music hall is suitable for exploring this physical and spatial relationship to the collective experience of music. The project involves exploring sound phenomena and the interaction between sound and emptiness in its formal and material properties. (Figure 15).

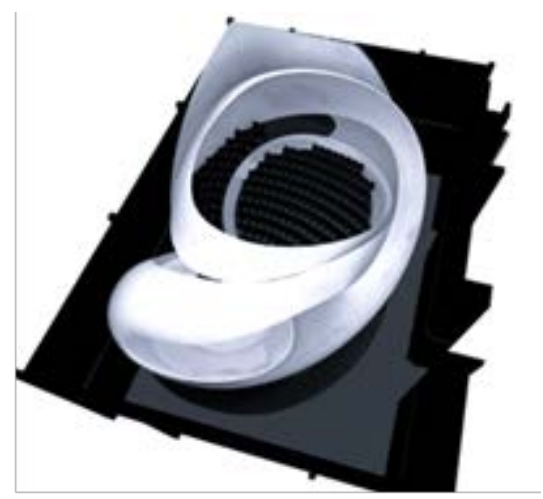

Figure 15. Chamber Music Hall

\section{Are Musical Chords Like Space?}

The parallels I have been pointing out between music and architecture - rhythm, emotion, meaning and the stereotype of genre - are well known and accepted. One comparison, however, is contentious: the equation between the spatial and time arts. Music has always been known as an art of time, whereas only in the last 150 years has architecture has been claimed as the art of space, even more than sculpture. From Sigfried Giedion to Bruno Zevi (by way of Frank Lloyd Wright and Le Corbusier), most critics and architects have insisted on the point. But there is one big mismatch. Music must be experienced in a linear sequence, while architecture takes in three-dimensionally at a glance, or holistically, as Gottfried Semper averred; and it is even moved through as a series of whole pictures. Architecture does not move in time, even Futurist architecture does not move. This initial divergence between music-time and architecture-space becomes all the greater because they are experienced through wholly dissimilar organs; and also, light waves versus sound waves. But consider the counter argument. (Note 5)

This 'space-music' is overpowering. It certainly inflates critical metaphors (and mine), but is there anything more than that - that is, a deep connection between harmonic chords and architectural space? I think there is, especially 
when they are both used in a dramatic way, in a sequence that leads somewhere. Take the typical passage through an Egyptian temple complex. This is a natural drama of discovery as elements become smaller, darker and more meaningful; or the supreme architectural experience I have already mentioned, the journey up the Acropolis to the Parthenon. Both are examples of the 'architectural promenade' that Le Corbusier made the hallmark of his work. One musical equivalent of this promenade is, for instance, a song in the key of $\mathrm{C}$ which is repeated, then transformed, then moved away from the base key in order to finally return. Musicians use an architectural metaphor to describe this journey - 'the tune has a sense of going home'. A typical symphony will drive an organizational idea or leading chord to its culmination, and composers refer to this overall time-structure as its 'architecture.' So, the parallels work both ways.

Diagrams showing the Circle of Fifths, taken from The Architecture and Colour of Music. The major 12 keys start with $\mathrm{C}$ at the top (and progress or regress five piano keys), while the minor scale is on the inner circle, and some harmonic overtones apparent in the ratios. The Mersenne Star (top) was drawn in 1648, but the more regular harmonic relationships were only fine-tuned geometrically (or 'tempered') by JS Bach later, in the early 1700s. Note the mixing of colours, a chromatic scale, yet another metaphor like the geometric one (Figure 16).
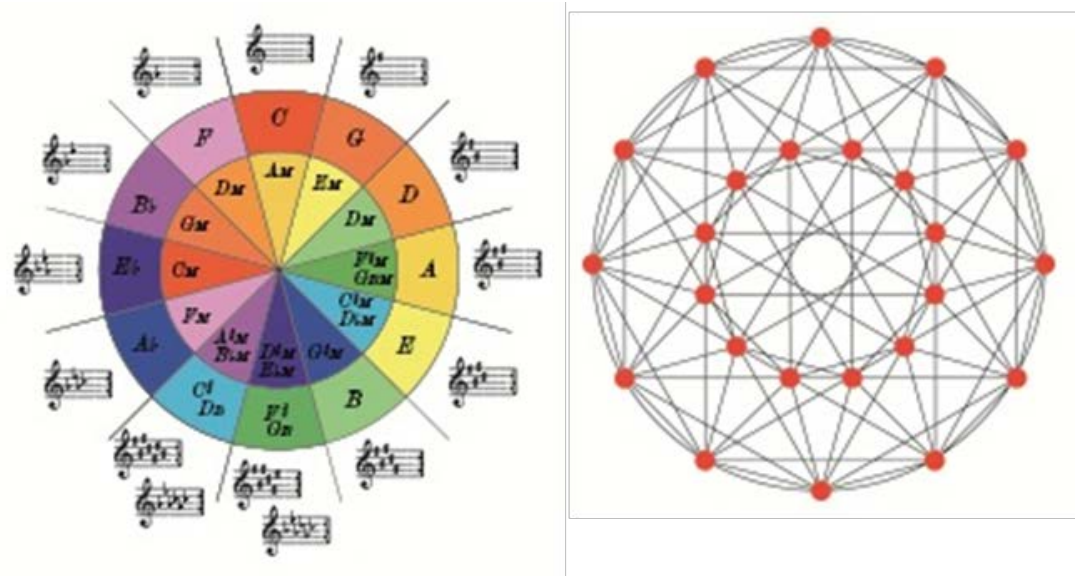

Figure 16. Diagrams showing the Circle of Fifths, taken from The Architecture and Colour of Music

Much like the constructions of Zaha Hadid and a lot of digital architecture in general, much of the surface is smooth. Visual music can compare it to the vulgar strings Wagner used.

\section{The Practical Experiments}

The idea of research (relationship between internal architecture and music) was applied to a sample of students of Design 2 in the department of interior design at the Faculty of Architecture and Design at Petra University in Jordan

The space of one of the shops to be applied to the area of $300 \mathrm{~m} 2$ located on the main street and the other side has been identified and there are no buildings above and the height of the ceiling is not specified

The shop is dedicated to selling albums, musical instruments and accessories for one of the world's or folkloric music types. Each student should choose one of the types of music and be studied thoroughly, while studying the culture and folklore that produced this type of music and musical instruments produced by the nature of each machine

In the beginning, students found it very difficult to connect music and interior design, and how to translate melody, rhythm and other means of producing music into architectural elements.

Students began to listen to the selected piece of music over and over again to live with it, then to subtract part of it and try to express the sound of each musical instrument with a specific design line, shape, hue, colour, colour and lighting all reflect the sound quality of the machine. To interior design. And how to express the imaginary things we hear and are not only in our minds only to a vacuum we live in and outlet various materials and colours and different contact multiple

\subsection{The First Project}

The first project of the student Malik Amara has chosen the Circassian music and studied everything related to Circassian culture, folklore, customs, traditions, clothing and colours. 
The legend says: "When God was free to distribute the land to the different peoples and peoples, the Circassians were left behind to occupy themselves with dancing, singing and composing music, and when they were done they went to God to see any part of the land that had been allocated to them. And the Lord took pity on them, and when he could not find the rest of the earth, he had to cut off part of heaven to put down their grief “

The former Circassian myth tells us two main things about the Circassians: first, they are obsessed with music, dance and singing, and the second is that they are old enough and with a wide imagination to come to the legend of everything that may fall on an eye or hear an ear. But legends, as mythologists say, are always real or inspired by reality. None of us will have a hard time identifying the source of the previous myth if he is allowed to wander around the land of the Caucasus, whose beauty can only be explained by similar legends. (Figure 17).

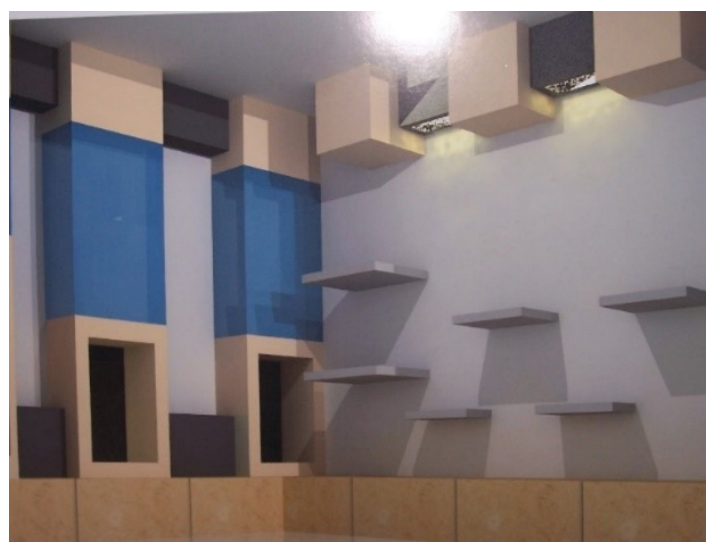

Figure 17. Interior Design by Malek

Circassian music has been used to document and chronicle harsh wars with the Russian Empire since the 18th century, culminating in massacres and mass forcible deportation of the Circassians to the Eastern Mediterranean.

After the study, it was found to be a dizzying dancer, based mainly on the accordion machine, which included singing and singing. The student listened to the music and analysed it with sound instruments and printed the rhythmic layout for his study. He found that it is a music of close frequencies and close frequencies between frequencies. A quick It is also characterized by the exchange of dialogue between different musical instruments in the presence of a strong rhythm of drums.

He then translated all this into a distinctive form of space containing architectural elements expressing his sense of this type of music. These elements were characterized by force (cubes) and compound repetition with a variety of elements and strong protrudes from the wall, the roof and Direct lighting

\subsection{The Second Project}

The student Jude Rachidat has chosen $\underline{\text { Spanish }}$ music

Flamengo was greatly influenced by the Eastern Byzantine rhythm, the early Andalusian song and the inherited song. This is especially true to the tradition of several villages near Granada, inhabited by the Morskians. This type of song shows how influenced Flamenco, Arabic and Indian song and the great similarity between Andalusian song and Flamenco. (Figure 18).

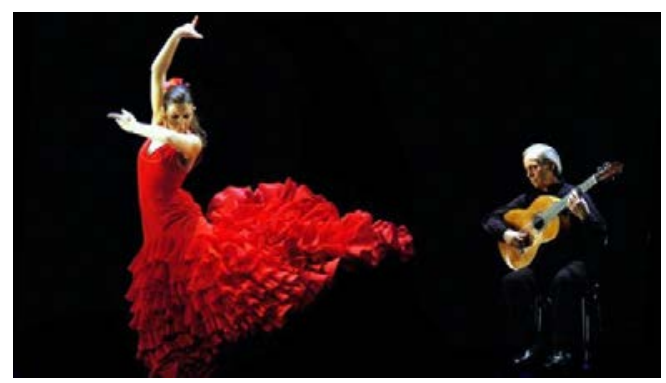

Figure 18. Flamengo dancing 
Flamengo consists of three elements: singing (Canute), dancing (bile) and playing guitar (guitarra) or guitar, in addition to the palm as group of hand applause

\subsubsection{Singing}

Is the center of the Flamenco group and the most important components of Flamenco. It is characterized by tragic, sad tones and shrill cries. The dancer should do his best with the body and limbs and move them to translate the words, feelings and meanings expressed by the singer. (Figure 19).

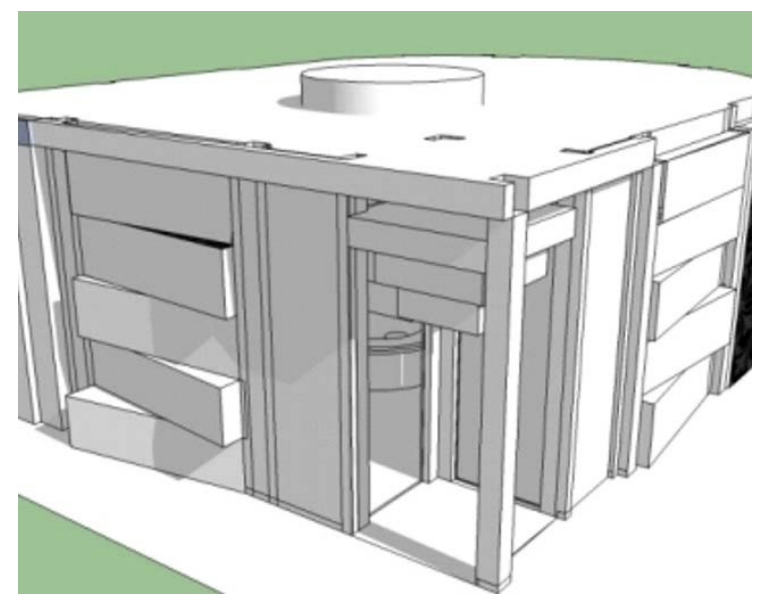

Figure 19. Designed by Jude Rachidat (Spanish music)

\subsubsection{Guitar}

Is the second component in the beginning of Flamenco was the singer is the basis of the artistic presentation and over time the guitar itself has been imposed by the talent and craftsmanship of the instrumentalists who have entered the art of Flamenco many of the outstanding musical techniques and plays an important role in the documentation of communication between the singer and dancer and achieve harmony and harmony. (Figure 20).

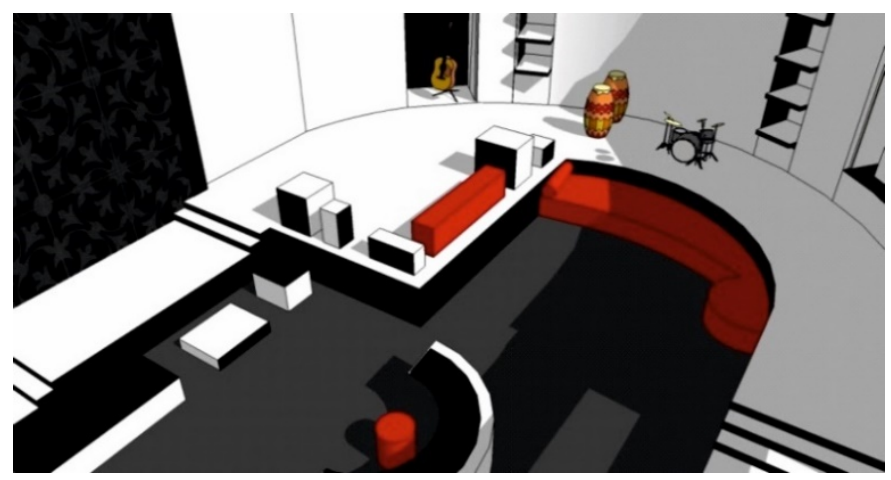

Figure 20. Designed by Jude Rachidat (ㅁanish music)

\subsubsection{Dance}

Which is the third component that embodies the emotions and emotions expressed by the song movements and steps, which controls the speed of the rhythm of the song through the speed and movement of the feet and the body as a whole and an important source of additional music arising from the movement of the singer and guitarist are always seeking to follow the steps rhythms and movements so it requires the dancer to be A skillful musician along with her physical fitness, which enables her to master the movements and hit the ground with her feet gracefully and forcefully expressive and quick and precise and precise and specific and move her hands and fingers and body soft and smooth and finite. (Figure 21). 


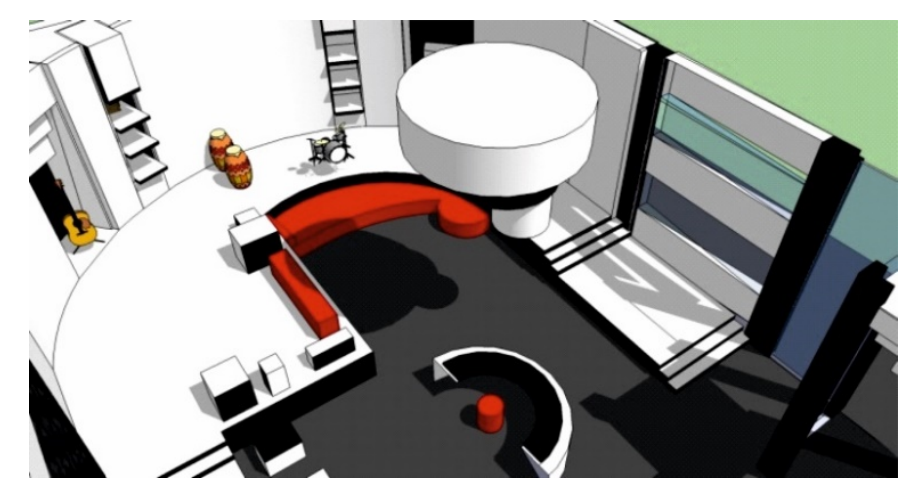

Figure 21. Designed by Jude Rachidat (Spanish music)

\subsubsection{Stickers}

They are an important element in this art. The accompaniment of flamenco is a complex rhythmic accompaniment. It is of utmost importance that precise laws must be adhered to. It is a rhythmic expression of words, notes and feelings. The function of the intellectuals is to motivate the dancer and support him by identifying the melody,

When she analysed this music, she found that it was a powerful rhythmic music based on rhythmic instruments on which the Spanish people dance their distinctive dances.

The student has taken advantage of all these distinctive elements of rhythms, colours, colours and folkloric elements to produce a design that expresses this music as the most accurate expression in terms of contrast between elements and sharp lines and different colours, such as red, black and white

\subsection{The Third Project}

\section{Student (Meena Munir) has opted for Scottish music}

There are many different forms of Folk music in Scotland, with very fluid rules. In fact, many artists, rather than simply sticking to one style, tread the line between two completely different musical styles. Ballads and laments are very popular in Scottish Folk music, normally sung by one singer with the backing of instruments, normally the harp, fiddle or bagpipes. Dance music is played across the country at dances, Highland balls, weddings and other ceremonious occasions. These dances include jigs, waltzes and reels, and are normally done accompanied by a group of musicians, a dance band or ensemble. The typical band includes six members, including one fiddle, two accordions, a piano or keyboard and bass and drums. However, this setup can vary considerably, and there is no strict fixed band setup in Scottish Folk music. Traditional Folk songs are often melodic and haunting, and vary from region to region. (Note 6) (Figure 22).

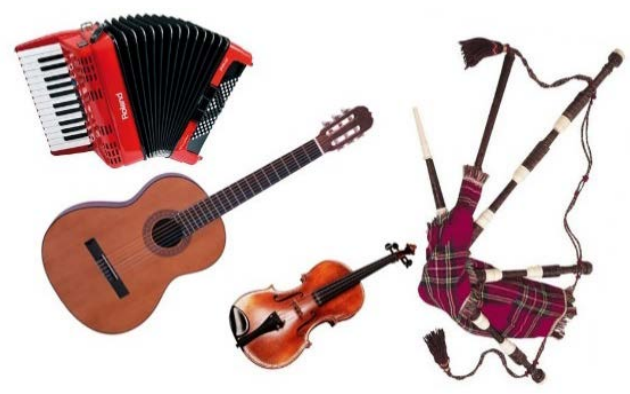

Figure 22. Scottish musical instruments

The Scottish Skirt with its distinctive colours and engravings was famous only when men wore it instead of women, and today it became an identity and a confirmation of national belonging in Scotland. (Figure 23).

We have to know that what the Scots are wearing and we call this "skirt" in their customs is a war dress.

More precisely, these skirts represent tribes and families hiding behind the red, green and blue colours and in the folds of each piece of cloth in addition to the "proximity music", which is its symbolic symbol associated with it.

The Scottish Skirt, called the "kilt", has its origins and customs when it is sewn and woven in colours that reflect the tradition and commitment of the various Scottish families in these skirts. 


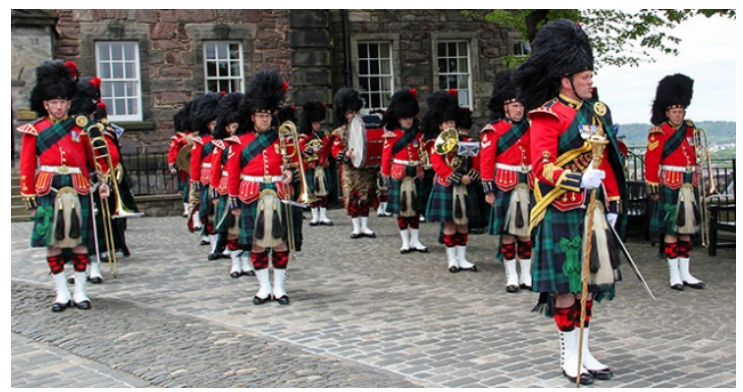

Figure 23. Scottish

The music is characterized by several musical instruments, most famous of which are bagpipes. Scottish music is a mountain music composed of a fundamental theme, then a series of movements is placed with the subject, and grows to become more complex each time. After the basic tone there are usually a number of differences (movement and change), which starts with the introduction of new instruments and musical tones, but with a continuous movement with the main subject and usually ends the piece back to the main subject. (Figure 24).

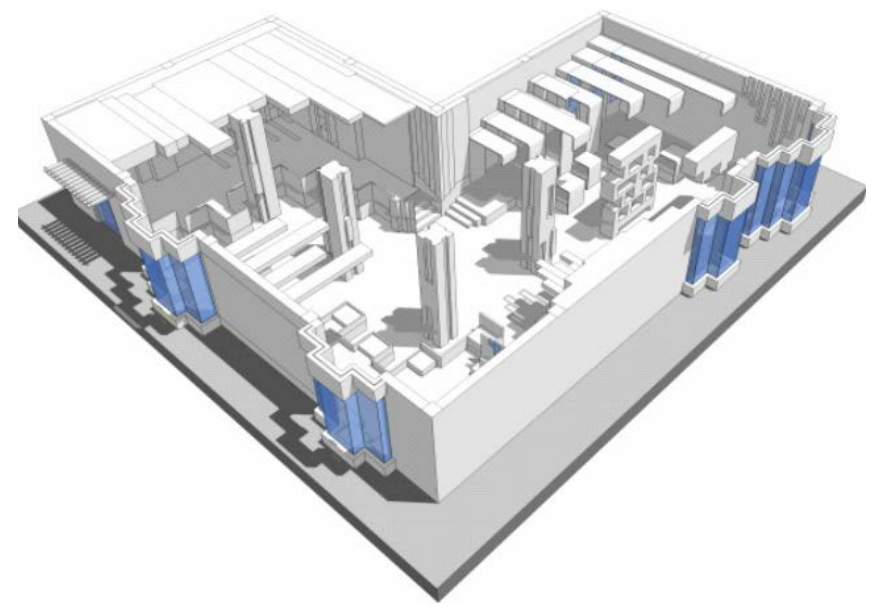

Figure 24.Shop. Designed by Meena Munir (Scottish music)

\section{Analysis results:}

- $\quad$ Type of continuity and non-interruption.

- $\quad$ Add new movements and merge them with the basics.

- $\quad$ Relatively sharp (straight lines - strong and explicit colors).

- $\quad$ Life and joy (movement).

\subsection{The Fourth Project}

The student Ruba Maghrabi and chose music (Enta Omry) to Umm Kulthum

Arabic and Egyptian music

According to the German researcher Dr. Sigrid Honicke in her book (Sun God of the West - the virtue of the Arabs in Europe) in a detailed chapter written by Zriab:

(The old singing music, like ancient poetry, does not know rhythm but depends on the weights that are confined to short and long sections.) The oldest church music dating back to the Middle Ages knows neither rhythm nor balance, but usually relies on the units of tones connected not the musical distribution, in the form of the division of verbal sentences by means of calls and the like, is a regular division. 
The rhythmic construction is authentic oriental. The rhythm helps to create (time limited music) and leads directly to the Mysore system. This may be the most important musical legacy that the Arabs gave to Europe, namely, the time-limited music that led directly to the creation of Mazoura. The theory of music in the Spanish-Arabic literature appeared in Latin works in the twelfth and thirteenth centuries.

The second heritage that Europe inherited in music from the Arabs is the Arabic melody. The Arab adherence to musical composition is observed in the horizontal principle, IE, the Arabic music does not include the Harmony, which is based on vertical combinations. This is the secret of the Arab tendency to the melodious music. (Note 7)

Musical instruments used are qanoon, oud, violin, cello, viola, contrabass, flute and drum. (Figure 25).

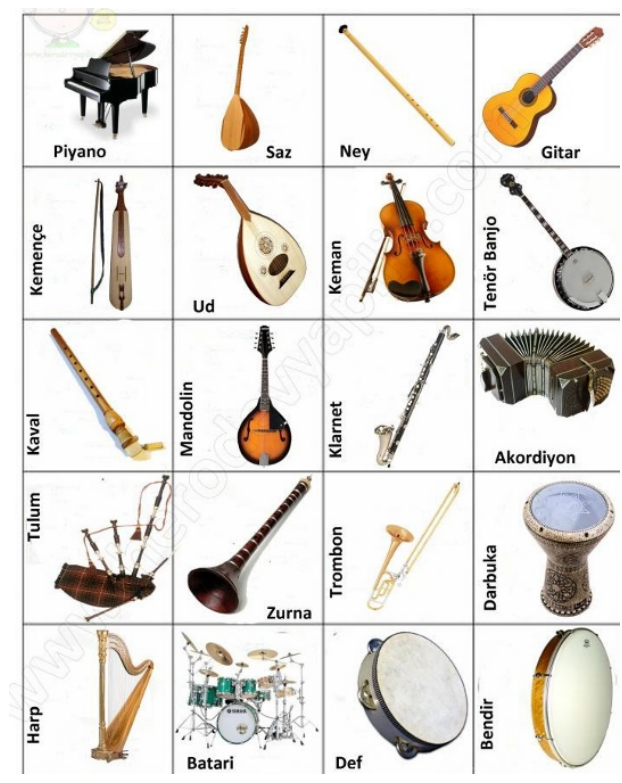

Figure 25. Arabic and Egyptian music musical instruments

Umm Kulthum was known for her extraordinary vocal ability and style. She was one of the greatest and most influential singers of the 20th century, where she has sold over 80 million records worldwide. Umm Kulthum is considered a national icon in her native Egypt and has been dubbed as the voice of Egypt and Egypt's fourth pyramid. She remains the most revered legendary singers in Egypt and the entire Arabic-speaking world._(Figure 26).

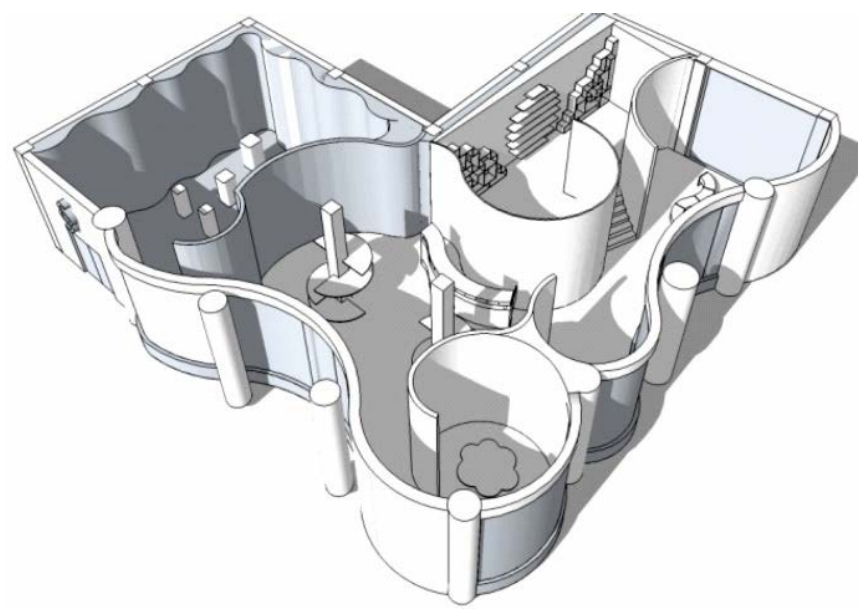

Figure 26. Shop. Designed by Ruba Maghrabi (enta Omry) to Umm Kulthum 
The quiet introduction begins with clicks from the sound of the large contrabass, filling the hall with its dominant end (the entrance by placing cubed display units expressing the clicks of the contrabass with the same units as the ceiling) accompanied along the path by manipulation of the law, so that it gradually begins to rise to the place of the Kurds and enter the violin to end the conclusion In a voice that resembles Western classical music. (entering the middle hall and the walls begin to dance with the violin). Clicking on the drum, a revolution of law. We feel that there is a dialogue like a loop between the guitar and the violin so that the guitar speaks in a sentence and the violin responds to the other, in the violin sounds like a whining. (Figure 27).

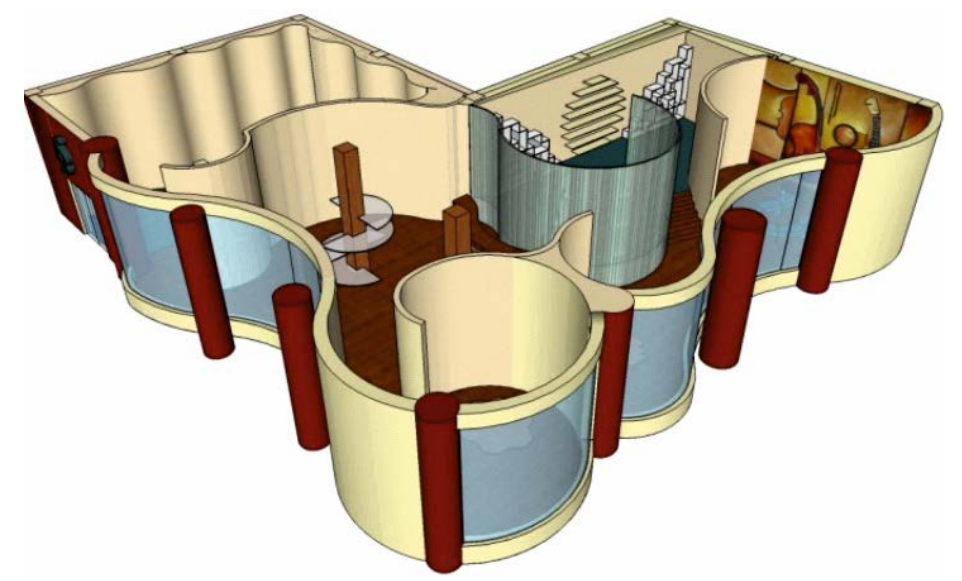

Figure 27. Shop. Designed by Ruba Maghrabi (Enta Omry) to Umm Kulthum

We note the ease and simplicity in the composition of the introduction were all based on one denominator is the Kurd. The colours used in the store are oriental colours: beige, brown, brown and blue. (Figure 28).

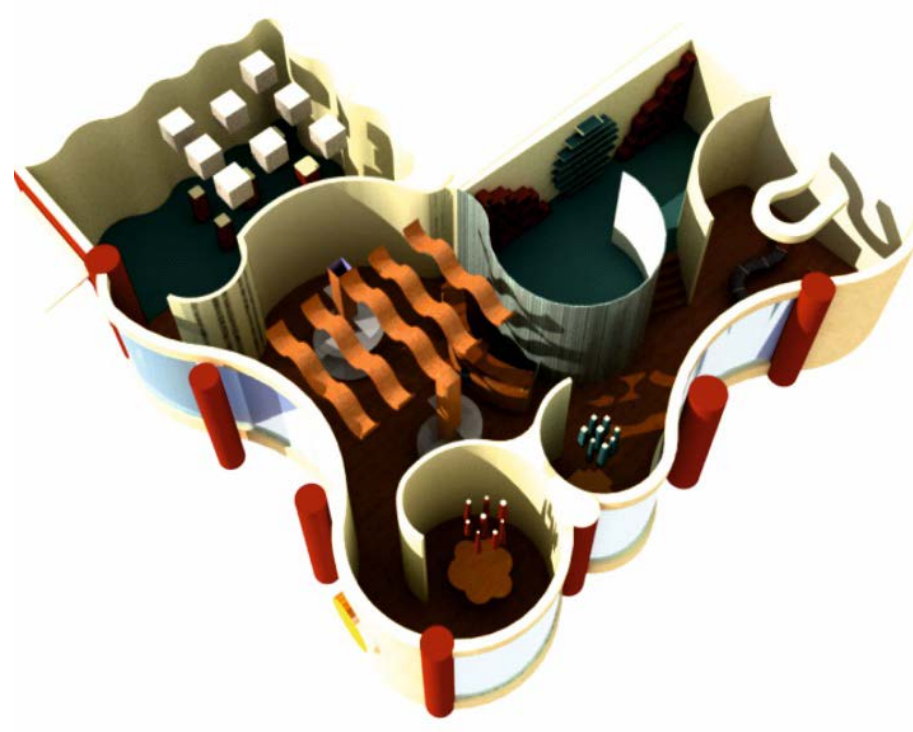

Figure 28. Shop. Designed by Ruba Maghrabi (Enta Omry) to Umm Kulthum

\subsection{The Fifth Project}

Presented by student Rola has chosen Indian music

Indian folk music.

Music has always been an important aspect in the lives of Indian people. India's rich cultural diversity has greatly contributed to various forms of folk music. Almost every region in India has its own folk music, which reflects the way of life. From the peppy Bhangra of Punjab to Garba of Gujarat to Bhavageete of Karnataka, the tradition of folk music in India is indeed great. Folk music is closely associated with farming and other such professions and evolved to alleviate the hardship and break the monotony of the routine life. Even though folk music lost its 
popularity with the advent of contemporary music like pop and rap, but no traditional festival or celebration is complete without folk music. (Note 8)

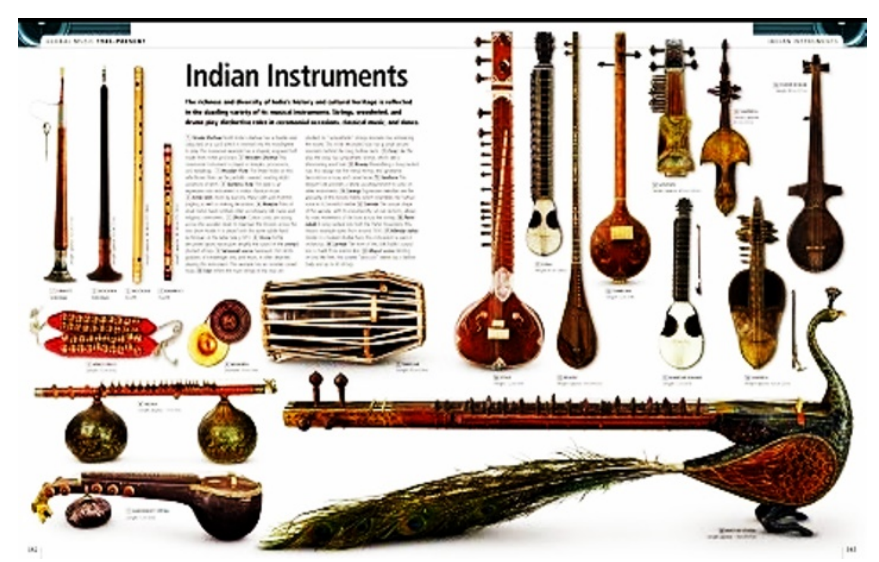

Figure 29. Indian folk music instruments.

Indian music relies on melody and rhythm rather than harmony. The colours that express the type of music that India is famous for, such as Khmer, Oily, Yellow, Orange and Beige were used. (Figure 30)

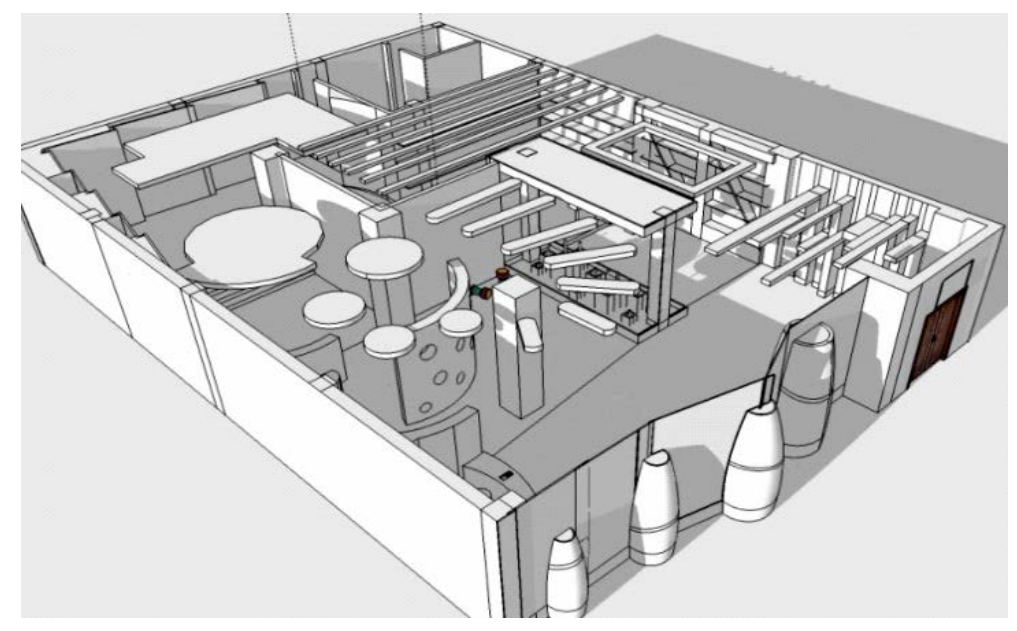

Figure 30. Shop. Designed by Rola (Indian music)

The melody was translated in the form of design elements expressing its rhythms and distinctive tones in a journey through the melody (the vacuum) from the beginning of the melody (the entrance of the shop) to the exit through the diversity in the form of design elements and their appearance or entry, colour, texture and material. (Figure 31)

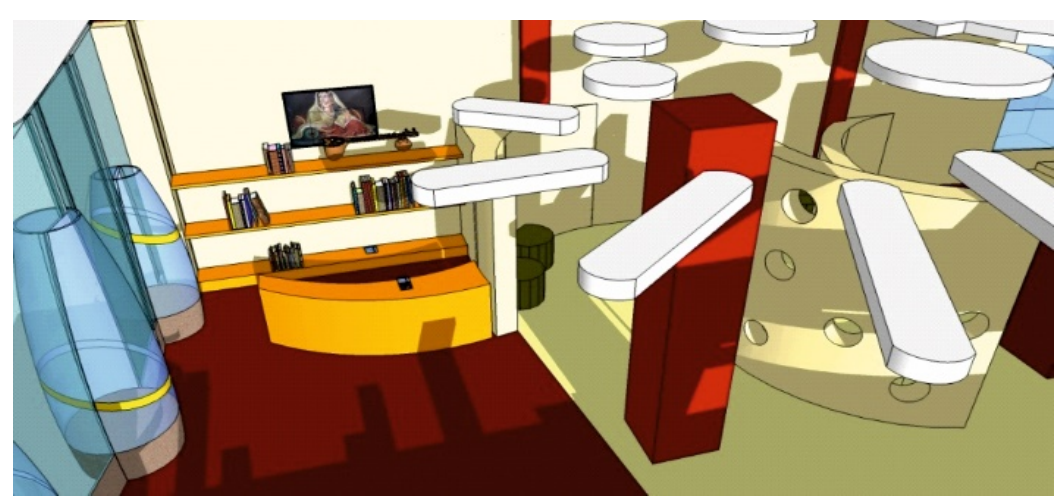

Figure 31. Shop. Designed by Rola (Indian music) 


\subsection{The Sixth Project}

\section{THE Godfather THIS MUSIC FOR THE PLAYER ANDRE RIEU}

Music Type: Classic

Born in Holland, he is one of the most famous violinists and leader of Maestro. He was famous for his innovative classical style

Music is not just a sudden expression separate from the environment surrounded by certain feelings in man, but it is a summary and abstract expression fused by all the experiences acquired by man during the course of his spiritual and material life, the music has never been separate from the reality of the pension, but is very affected by and influence, Music is the result of a culture of "place," which is like a living organism, is influenced, influenced, grown, moved, travelled, melded and fused with every human being moving from one place to another through time. Popular music is therefore the genetic footprint of every people. And the philosophy of each nation through its tones and sounds and even its machines.

The European classification of music is the typical music of any culture and of any people. Through time and public conviction, peoples classify their artistic works as classical when their beauty and effect is valid for all times.

Thus, European classical music, for example, can be described as Mozart (1756-1791, Bach 1685-1750, Shostakovich 1906-1975, etc.) Is a style of music or musical composition that spread in Europe between the 17th and 19th centuries? (Figure 32)

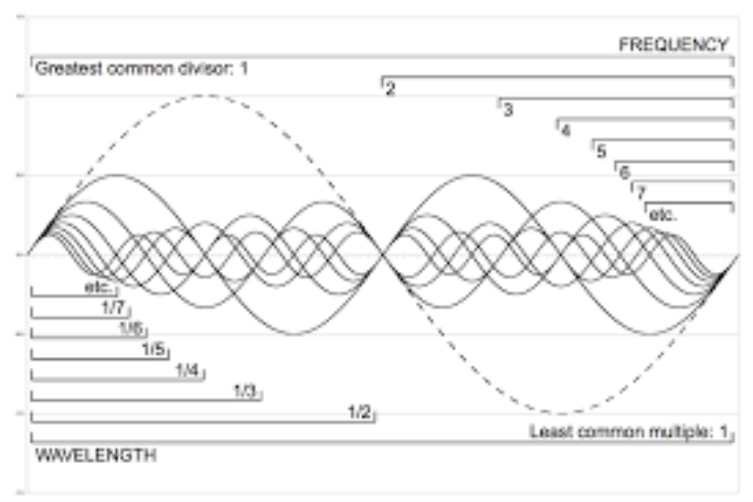

Figure 32. Motion Path. The sound graph of the Classic music

Some of the most important instruments used in European classical music:

Kettle Drum -Violin- Accordion - Harmonica- Saxophone

The cello is one of the members of the family of string instruments. It is characterized by its soft and deep voice. It also has a wide sound area that enables it to produce big sounds (bass), sharp sounds (sopranos)

Piano "is the short and full name of the full name Piano-Forti, which means" weak-strong "in Italian.

Flute: Flute is considered the latest development of one of the oldest musical instruments known to man as the "flute". In ancient times, primitive human bones and hollow stems were used to produce sounds by blowing inside the hollow pipe at a certain angle. (Figure 33) 


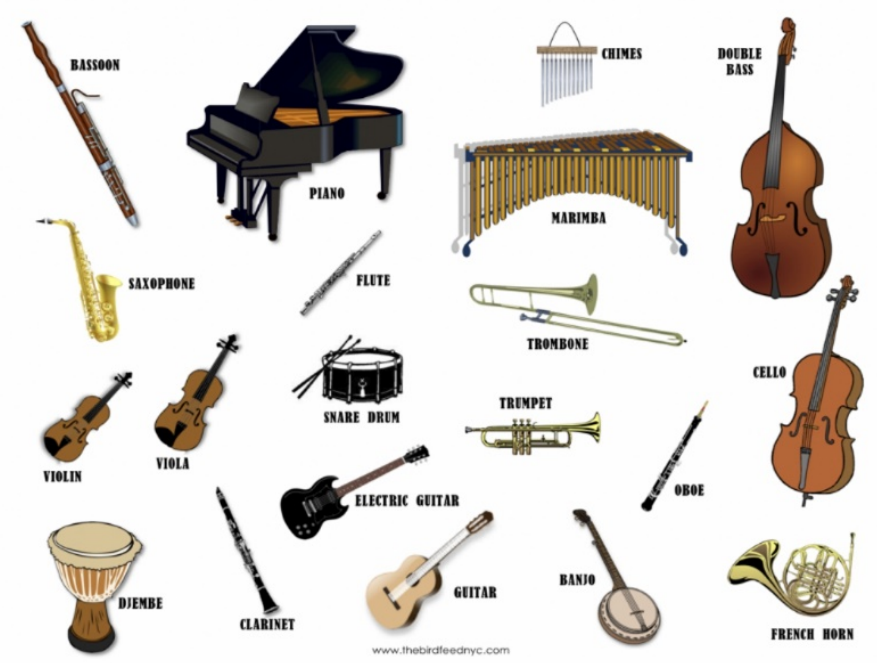

Figure 33. Classical musical instruments

\section{Design Idea: Dreams}

The design comes from a sense of selected music, which gives a sense of gradual transition from the real world. The physical world. To the world of imagination and spirituality. The world of dreams and romance. Motion Path. The sound graph of the music is used to strip the lines and draw them in curves and apply them to the space to give a wavy movement within the space. The path is not straight, but the track forces the person to move around in the space. This is done by moving from reality to dreams through a path that begins with a low rise and then a multilevel to reach a high area expressing dreams. The entrance to the space begins with a low ceiling - a few lightings - dark colours - and smooth materials. Then a gradual transition begins within the space where the path of the movement changes and the ceiling begins to rise, and the lighting comes from the windows - and the colours turn white until we reach a wide area and the ceiling height is as high as possible and the light is spread from the ceiling and the use of simple materials that express transparency and romance like silk and water. (Figure 34)

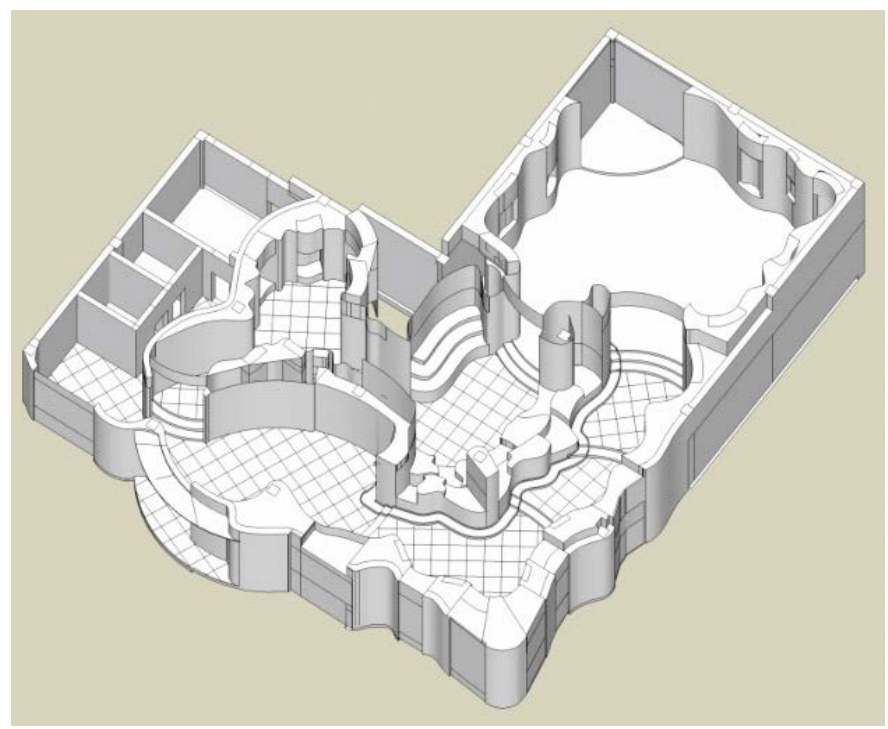

Figure 34. Shop. Designed by ghadeer (Classic music - Godfather)

\subsection{The Seventh Project Russian Folk Music - Student Razan Al-Hammouri}

The roots of Russian folk music date as far back as in the middle of the first millennium AC, when Slavic tribes settled in the European part of the present territory of Russia. Those tribes were famous for their love and mastery of music, singing and dancing. From generation to generation folk ensembles and singers try and keep up the 
authentic Russian music traditions alive. Folk song and dance ensembles present old country repertoire with songs often blending pagan roots and Christian symbolism, songs either sad and drawling or merry, as well as dances dignified and graceful or rollicking and vigorous, accompanied by traditional musical instruments (balalaikas, whistles, guslis, wooden spoons, bayan, etc.) and colourful costumes. These days enjoy the 'new folk wave' bringing together old traditions, modern technologies and experimental music styles. (Figure 35)

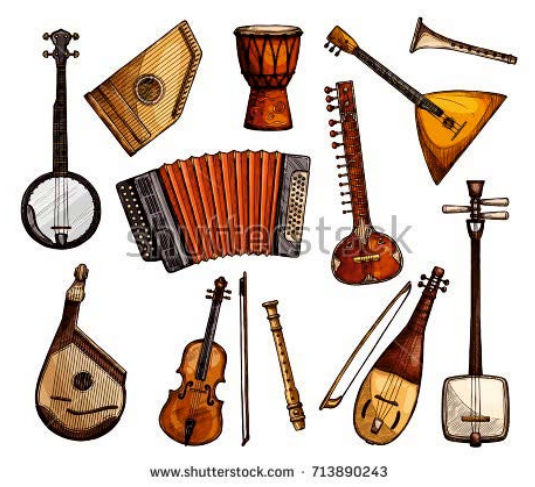

Figure 35. Russian musical instruments

In examining the student of Russian music reached it with the rhythm of the dance music sharp and fast and fun accordion uses instruments such as the violin. The requesting and the expression of the music high tape wraps through the vacuum and sometimes in the ceiling and walls, as well as breaking the component units of the ground for the Cashier Counter smiles and chairs for seating in the dancing curves and reflective in all directions requesting used white color pan vacuum and Intricateness of the nature of Russian lands covered with snow with the harmony of shades of gray and vaccinate tapes distinctive colours and folklore of the Russian people, blue, red, with the use of these tapes also lighting units. (Figure 36-37-38)

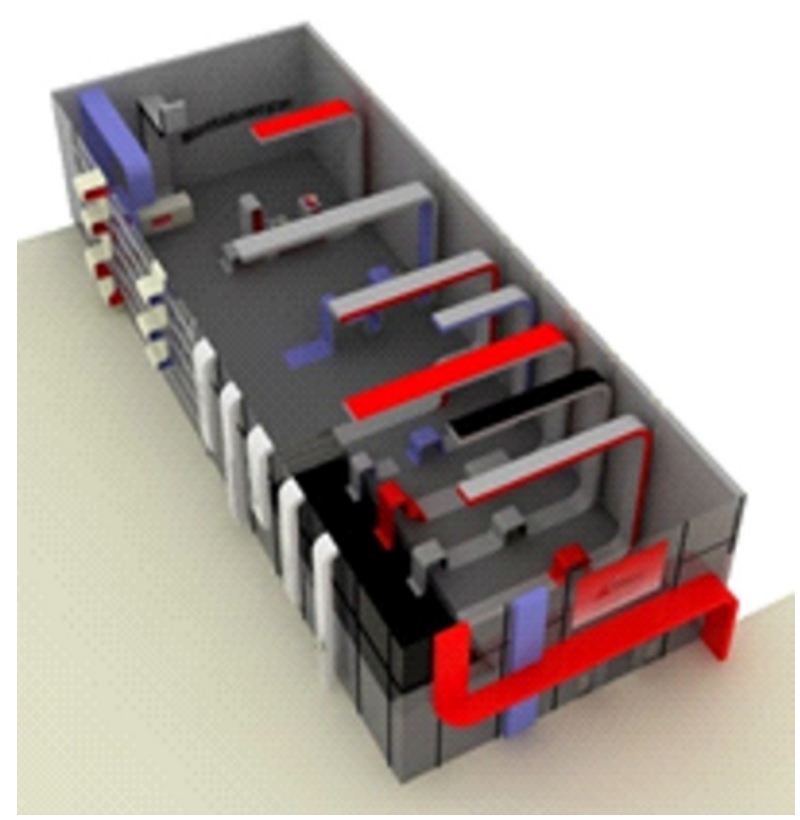

Figure 36. Shop. Designed by Razan (Russian musical) 


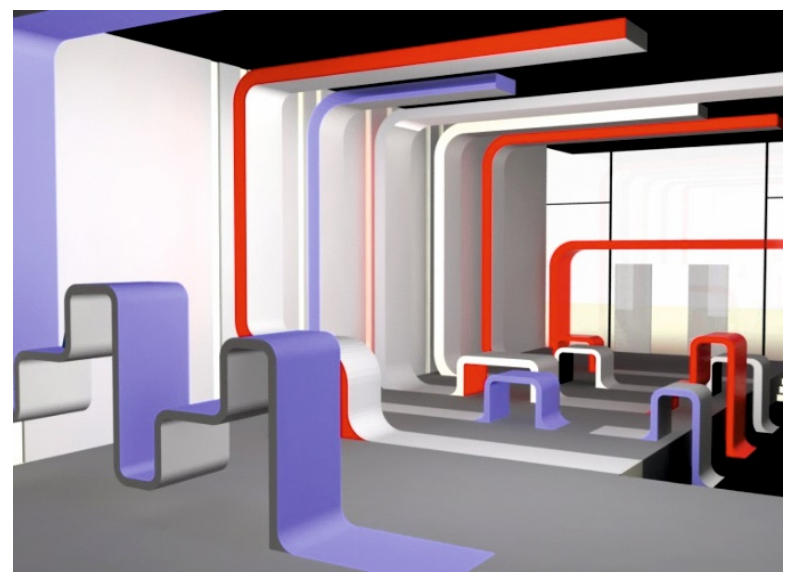

Figure 37. Shop. Designed by Razan (Russian musical)

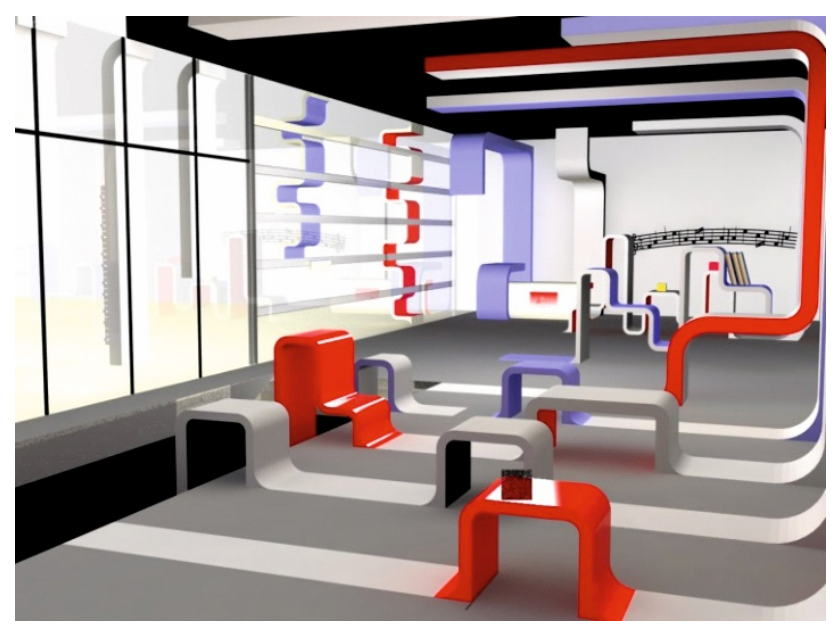

Figure 38. Shop. Designed by Razan (Russian musical)

\section{Summary of some students' work}

The music We can also "enjoy it" without "studying it" by using our senses to "see what we listen to" and "hear what we see" in order to achieve higher levels or meta-experiences. I think that is what genius people "normally" do, they use their senses to experience the world in different way than we do!
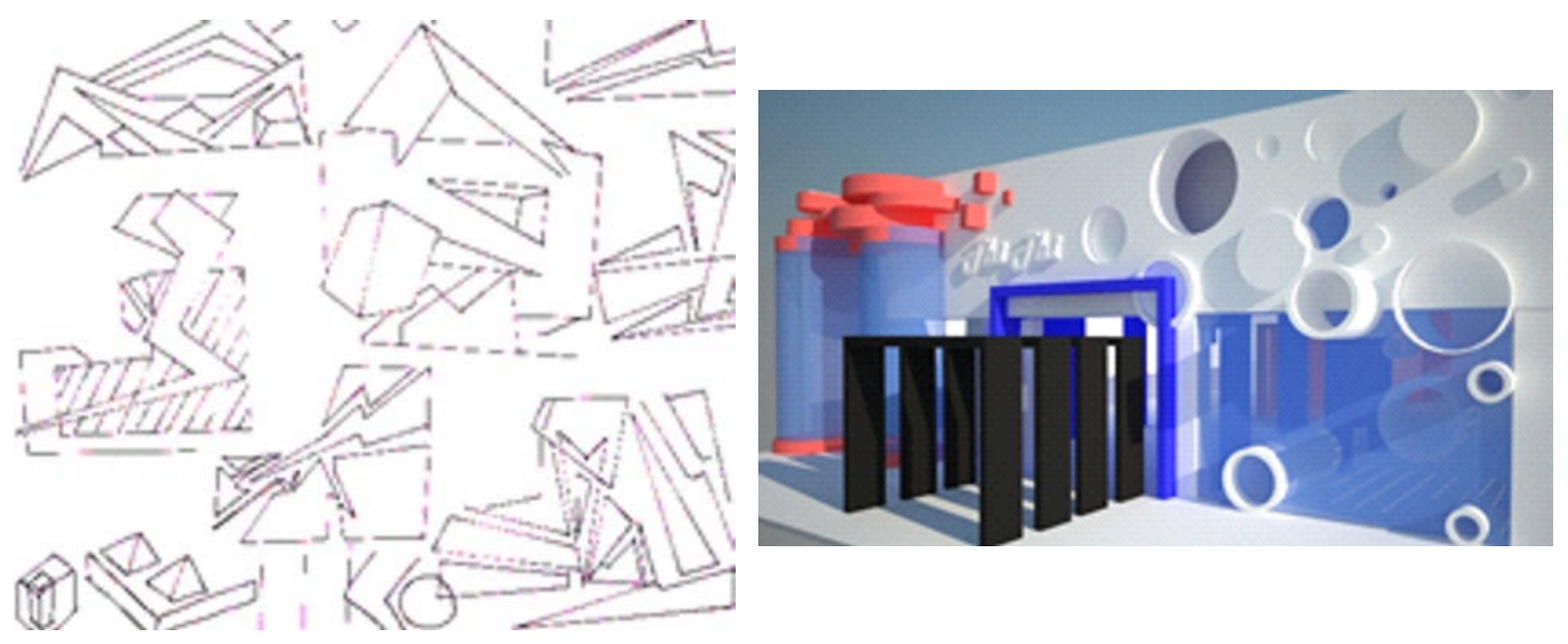


\section{Results}

1. The student was trained to use the basics of interior design with a structured and creative thought.

2. Developing the student's ability to control the inner space and all its elements according to one system, layout and melody to produce a free interior design.

3. Sensitize the sensual feelings of the student and train his senses on how to express his inner feelings and bring them into physical existence in a concrete and realistic form.

4. Develop the student's ability to read the aesthetics of interior design and criticism

5. It was observed that the relationship between music and architecture resides through.

6. Proportionality is the most important link between music and architectural design since proportionality is what gives both beauties.

7. The time between rhythms and tones is the distance between the elements in the architectural design and the tone is the form in the design.

8. As some musicians have turned some mathematical theories and aesthetic golden proportions into music to prove that aesthetic aesthetics must produce beautiful music that bears a beautiful fit between the tones and the time between each and every tune.

9. The designers also translated the music into a design by translating geometric logic directly into points, lines, surfaces and forms to prove that the beautiful music in its beautiful proportion produces a beautiful architectural design with the same qualities as the translated music.

10. Transforming music into a design through the sensation, feeling and impression of a music in the same designer to translate these feelings into design forms and stereoscopic elements with materials, colours and illuminations that express these feelings and the emotional state raised by this music.

11. Each musical instrument has a special nature that is similar to some design methods and is similar to design elements in its own right and through the characteristics of some musical instruments. For example, some of these instruments were classified with the appropriate elements of architectural design as a necessary link between music and architectural design.
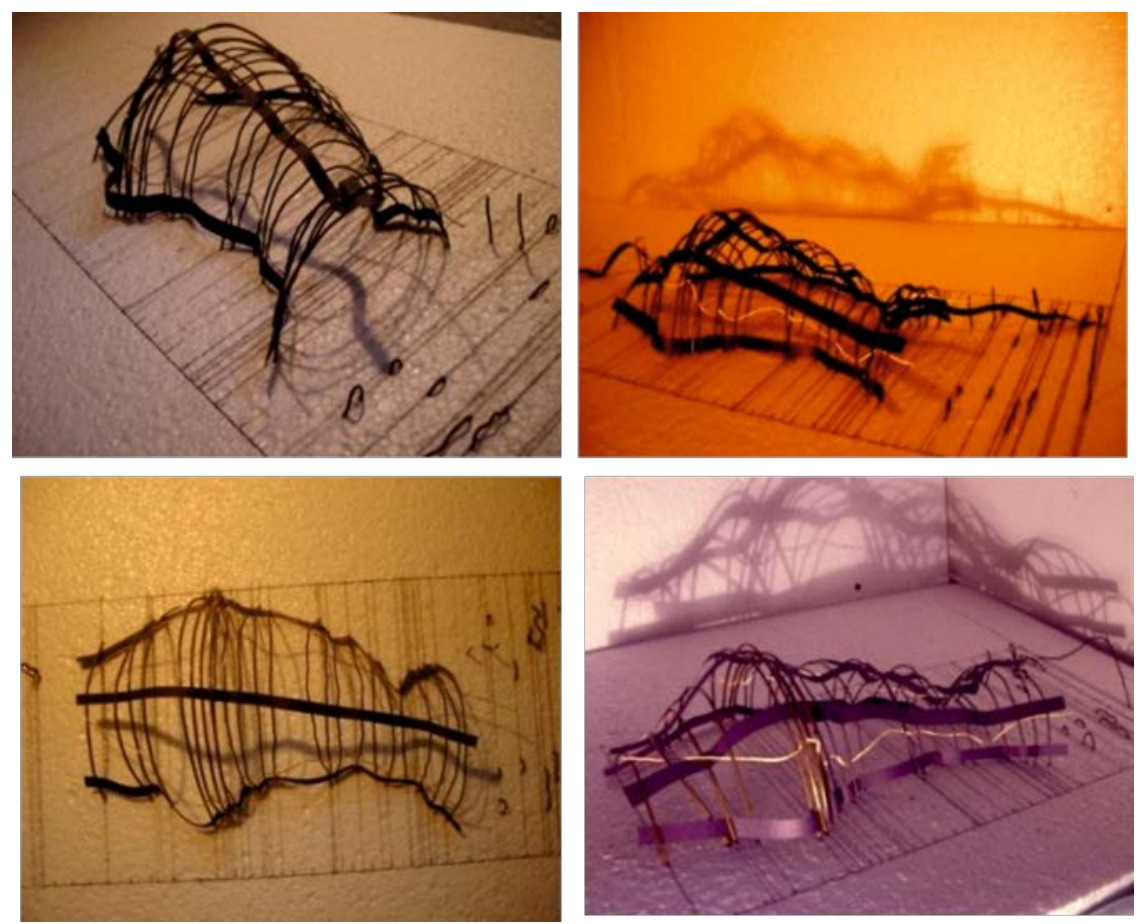


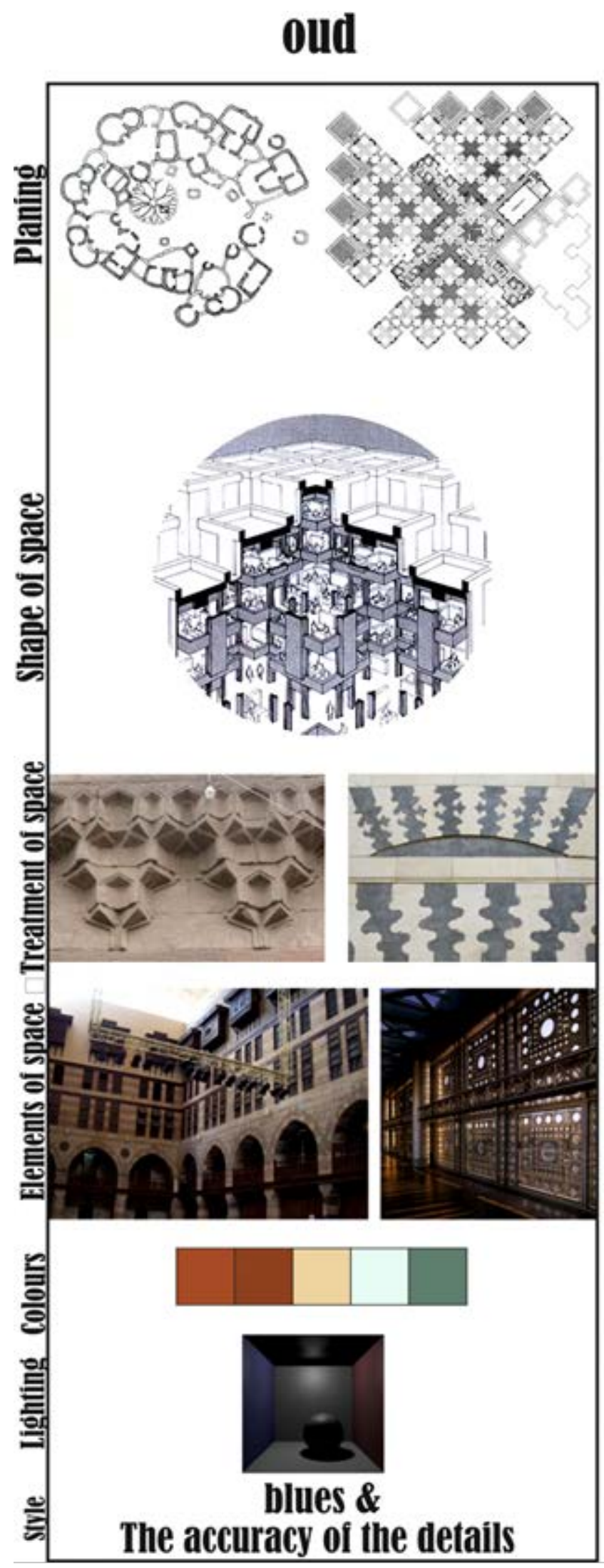

\section{Violin}

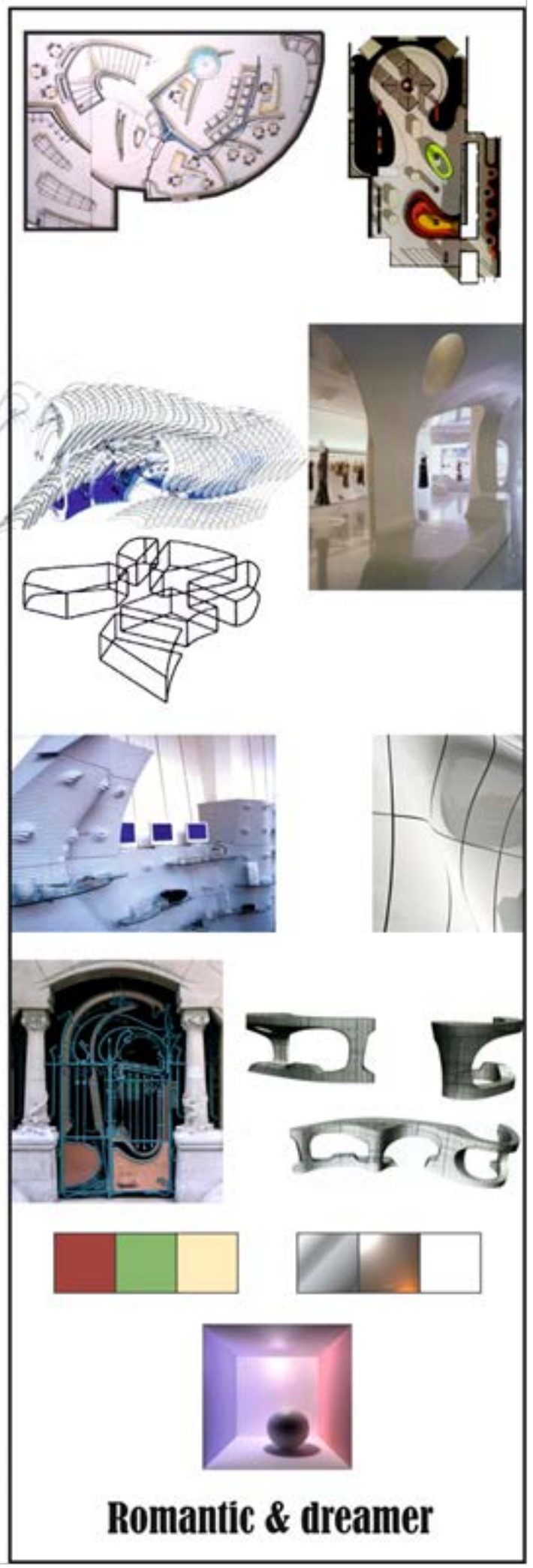




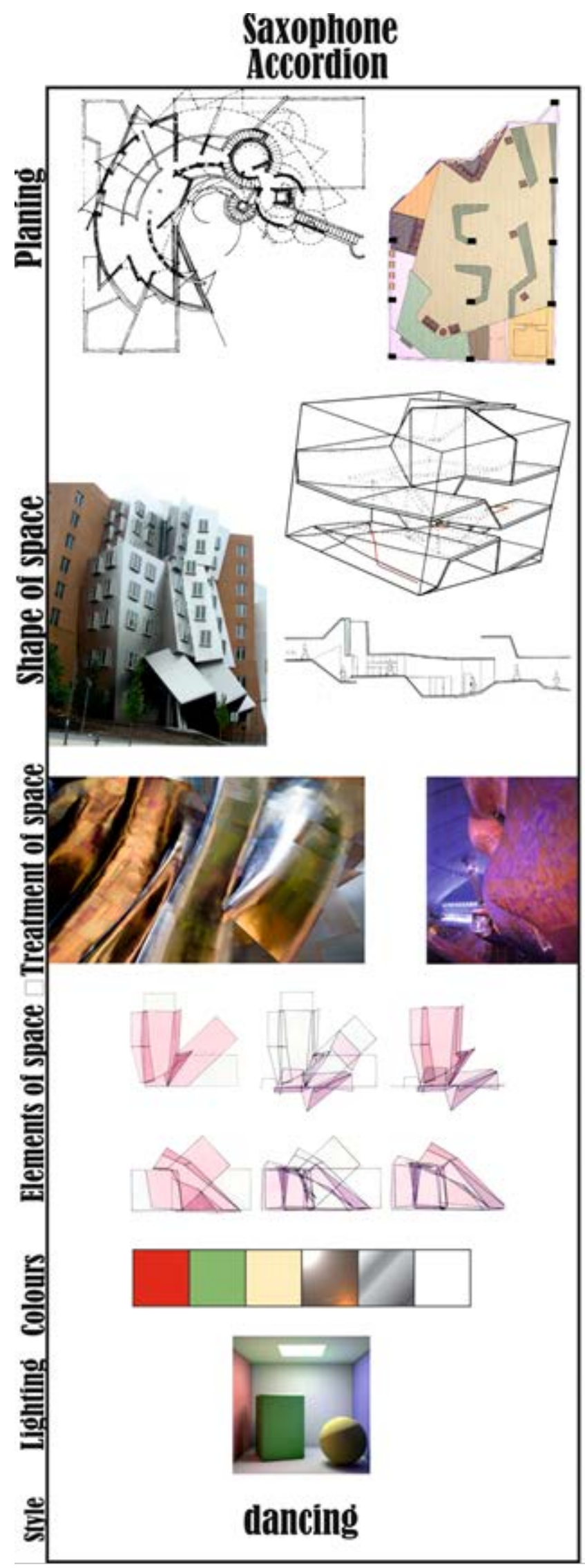

Piano

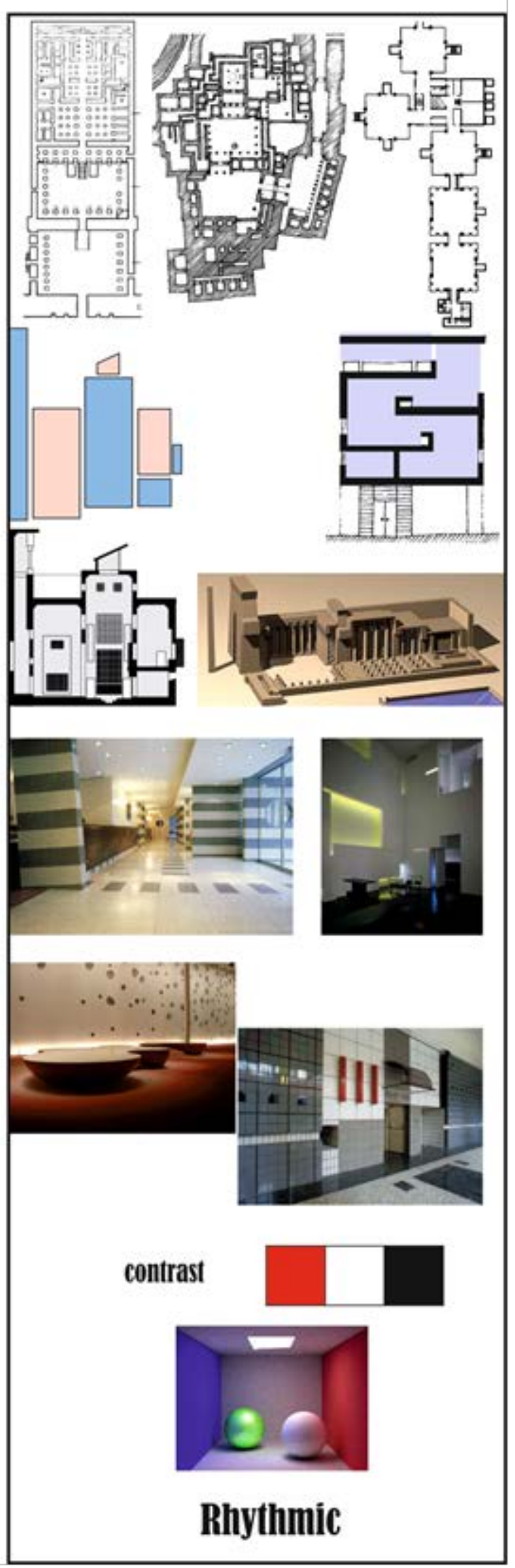




\section{The Recommendations}

1. The researcher is recommended to introduce students of interior design to the importance of music in the refinement of the soul and feelings

2. It is also recommended to teach music to students of interior design

3. It is also recommended to train students on the strong relationship between music, architecture and interior design. Music teaches students a lot of rules and rules of interior design indirectly and organizes their ideas and subject to the elements of interior design to regulate the beauty may reach the level of rules and laws governing the work

\section{References}

Bankhead, D. (2014). MUSIC \& AUDIO - MUSIC THEORY - Understanding Harmony: Part 1- 31 Jan 201423066.

Cultural India: Indian Music: Folk Music of India.

Jencks, C. (2013). Architecture Becomes Music 6 MAY, 2013.

MB - Folk Music - A Guide to Folk Music of the World - Scottish Folk Music - on AUGUST 28, 2007.

Midobashamido (2018). Arabic and Egyptian music - (56) in music - 24-2-2018.

Ross, A. (2011). Musical Events, Waveforms. The singular Iannis Xenakis.

The Architectural Itinerary Iannis Xenakis (Sven Sterken) An Invitation to Play.

Xenakis, I. (2011). Graphicnotation.

\section{Notes}

Note 1. https://music.tutsplus.com/tutorials/understanding-harmony-part-1--audio-23066

Note 2. https://www.newyorker.com/magazine/2010/03/01/waveforms

Note 3. http://www.iannis-xenakis.org/xen/archi/architecture.html

Note 4. https://graphicnotation.wordpress.com/2011/03/02/003/

Note 5. https://www.architectural-review.com/essays/viewpoints/architecture-becomes-music/8647050.article

Note 6. http://www.music-folk.com/scottish-folk-music/

Note 7. https://steemit.com/music/@midobashamido/article-about-arabic-and-egyptian-music

Note 8. https://www.culturalindia.net/indian-music/folk-music.html

\section{Copyrights}

Copyright for this article is retained by the author(s), with first publication rights granted to the journal.

This is an open-access article distributed under the terms and conditions of the Creative Commons Attribution license (http://creativecommons.org/licenses/by/4.0/). 